\title{
Integrated in silico and 3D in vitro model of macrophage migration in response to physical and chemical factors in the tumor microenvironment
}

\author{
Lee, Sharon Wei Ling ${ }^{1,2,3,+}$, Seager, R.J. ${ }^{4,+}$, Litvak, Felix ${ }^{4}$, Spill, Fabian ${ }^{4,5,6}$, Sieow, Je Lin ${ }^{3}$, Penny, \\ Hweixian Leong ${ }^{3}$, Kumar, Dillip ${ }^{3}$, Tan, Alrina Shin Min ${ }^{3}$, Wong, Siew Cheng ${ }^{2,3}$, Adriani, Giulia ${ }^{3, *}$, \\ Zaman, Muhammad H ${ }^{4,7, *}$, Kamm, Roger Dale ${ }^{5,8, *}$
}

1 BioSystems and Micromechanics IRG, Singapore-MIT Alliance for Research and Technology, Singapore, 138602, Singapore

2 Department of Microbiology and Immunology, Yong Loo Lin School of Medicine, National University of Singapore (NUS), Singapore, 117597, Singapore

3 Singapore Immunology Network (SIgN), Agency for Science, Technology, and Research (A*STAR), Singapore

4 Department of Biomedical Engineering, Boston University, Boston, MA, 02215, USA

5 Department of Mechanical Engineering, Massachusetts Institute of Technology, Cambridge, MA, 02139, USA

6 School of Mathematics, University of Birmingham, Birmingham, B15 2TT, UK

7 Howard Hughes Medical Institute, Boston University, Boston, MA, 02215, USA

8 Department of Biological Engineering, Massachusetts Institute of Technology, Cambridge, MA, 02139, USA

+ These authors contributed equally to the work.

* Corresponding authors.

Roger Dale Kamm, Email: rdkamm@mit.edu

Muhammed H Zaman, Email: zaman@bu.edu

Giulia Adriani, Email: giulia_adriani@immunol.a-star.edu.sg 


\begin{abstract}
Macrophages are abundant in the tumor microenvironment (TME), serving as accomplices to cancer cells for their invasion. Studies have explored the biochemical mechanisms that drive pro-tumor macrophage functions, however the role of TME interstitial flow (IF) is often disregarded. Therefore, we developed a three-dimensional microfluidic-based model with tumor cells and macrophages to study how IF affects macrophage migration and its potential contribution to cancer invasion. The presence of either tumor cells or IF individually increased macrophage migration directedness and speed. Interestingly, there was no additive effect on macrophage migration directedness and speed under the simultaneous presence of tumor cells and IF. Further, we present an in silico model that couples chemokine-mediated signaling with mechanosensing networks to explain our in vitro observations. The model proposes IL-8, CCL2 and $\beta$ integrin as key pathways that commonly regulate various Rho GTPases. In agreement, in vitro macrophage migration remained elevated when exposed to a saturating concentration of recombinant IL-8 or CCL2, or to the co-addition of a sub-optimal concentration of both cytokines. Moreover, antibody blockade against IL-8 and/or CCL2 inhibited migration that could be restored by IF, indicating cytokine-independent mechanisms of migration induction. Importantly, we demonstrate the utility of an integrated in silico and 3D in vitro approach to aid the design of tumor-associated macrophage-based immunotherapeutic strategies.
\end{abstract}




\section{INTRODUCTION}

Interstitial flow (IF) is an important, yet underappreciated, biophysical force that drives cancer progression [1]. It is derived from an elevated interstitial fluid pressure (IFP) in the solid tumor $(\sim 10-40 \mathrm{mmHg})[2,3]$, due to highly permeable tumor vessels and the lack of functional lymphatic vessels $[4,5]$. This abnormal pressure results in a steep pressure gradient near the tumor margin with escape of interstitial fluid from the tumor mass into the surrounding tissues [6-8], where IFP then drops rapidly to normal tissue values $(\sim 0$ $\mathrm{mmHg}$ ) $[4,9]$. Because this fluid contains tumor-secreted cytokines and growth factors and can influence tumor cell migration, IF essentially fuels tumor metastasis $[9,10]$.

Clinical data across different solid cancers have shown that higher IFP at the tumor site strongly correlates with poorer patient survival [11-14]. Accordingly, IFP has been viewed as a strong prognostic factor that is independent of other clinical parameters $[11,15]$, with ongoing effort to develop strategies to decrease IFP, and hence IF, in patients [16-21]. However, given the complexity of cancer pathology, current findings have only begun to explain the multiple interacting facets of IF's role in cancer, including its regulation of pivotal immune cell players in the tumor microenvironment (TME). This scenario motivates the need for additional studies that investigate the role of IF on multiple cell types in the TME.

Macrophages are highly abundant at the tumor-stromal boundary [22-24], where there are high levels of IF $[25,26]$. Interestingly, this is also where there are high rates of tumor cell invasion $[25,26]$. Clinical and experimental evidence report that macrophages crucially support tumor metastasis [27], with a metaanalysis showing that over $80 \%$ of studies correlate poor patient outcomes and macrophage density [28]. Moreover, intravital imaging of fluorescently labelled cells in mammary tumors has shown that tumor cells and macrophages move concordantly [24]. Indeed, growing evidence suggests that macrophages could be importantly involved in IF-based tumor cell invasion [25,29]. Therefore, interfering with the signaling pathways associated with IF, tumor cells and macrophages could potentially inhibit the pro-tumor function of macrophages and also tumor cell metastasis [30]. 
Macrophages remodel extracellular matrix (ECM) through matrix metalloproteinases (MMP) which degrade collagen and create tracks for tumor cells to migrate [31,32]. Such tracks also enable macrophages to migrate toward and interact with other cells in the TME to support tumor progression, for example by their contact-dependent support of the epithelial-to-mesenchymal transition (EMT) of tumor cell aggregates [33], or their contact with the endothelium to increase its permeability to intravasating tumor cells [34]. Therefore, macrophage migration in the TME is an important parameter that reflects their ability to support tumor cell invasion through the ECM in the process of metastasis [35]. Current understanding of macrophage migration has been confined to the regulation by biological cues in the TME, including tumorsecreted factors (TSF) which have been identified as key regulators of macrophage motility [36-40].

The study of cell migration requires suitable experimental models that allow cells to migrate with spatial and temporal freedom, while allowing for real-time measurements. A classical set-up is the transwell migration assay, where cell motility is assessed by the number of cells that migrate across a twodimensional (2D) porous membrane between upper and lower chambers $[41,42]$. While the use of such platforms contributes insight toward cell motility, they lack a 3D ECM and fail to accurately mimic the physiological setting $[43,44]$. Specifically, recent studies have reported differences in protein expression when cells migrate through a 3D matrix compared to their migration on a $2 \mathrm{D}$ substrate $[42,44-46]$. For example, focal adhesion kinase (FAK) is crucial for migration through a 3D matrix, but in 2D, FAK-null cells can compensate for migration defects by over-expressing other cell migration machineries [46]. Moreover, matrix degradation, an important factor in 3D migration, is not required for migration on a 2D surface. Indeed, there is evidence that $3 \mathrm{D}$ measurements of migration directedness (ability to maintain direction of motion) and speed do not correlate with migration in 2D [45]. Finally, these classical assays present end-point readouts of the number of transmigrated cells, failing to capture the temporal dynamics of cell motility. 
On the other hand, microfluidic models present suitable 3D environments for real-time measurements of migration directedness and speed. However, current microfluidic models of IF comprise a gel-based monoculture of cells including tumor cells $[47,48]$, fibroblasts $[49,50]$ or macrophages [51]. The most cellularly complex model has tumor cells seeded in a central microchannel with an additional endothelial monolayer in the adjacent microchannel [52]. Recently, Li et al. report evidence that IF increased the migration directedness and speed of mouse macrophages using a single-gel microfluidic platform [51]. However, there remains open questions such as how IF which specifically arises from tumor cells can dynamically modulate macrophage migration, and whether IF or TSF is the stronger determinant of macrophage migration behavior. To this end, the in silico modelling of in vitro data can yield quantitative insight into the biological signalling and biomechanics of macrophage migration in a 3D TME setting [53,54].

The present work seeks to address these unanswered questions by developing a human-based microfluidic model comprising a co-culture of tumor cells and primary monocyte-derived macrophages, designed to impart the effect of tumor-derived IF and TSF on macrophages. Specifically, we will contribute insight toward the dynamic IF-associated interplay that exists between tumor cells and macrophages. Further, we will clarify if IF and TSF are functionally redundant or additive in regulating macrophage migration, thus identifying their relative importance as potential therapeutic targets. Moreover, we explore how our in vitro data contributes toward the development of a refined in silico signaling network model that associates TSF, IF and the migration activity of macrophages. 


\section{MATERIALS AND METHODS}

\section{Generation and culture of GFP stable cell lines}

A human pancreatic adenocarcinoma (PDAC) cell line, Panc1 (ATCC ${ }^{\circledR}$ CRL-1469), and normal pancreatic epithelial cell line hTERT-HPNE (“HPNE”) (ATCC ${ }^{\circledR}$ CRL-4023) were transfected to stably express green fluorescent protein (GFP). GFP gene was amplified from pGreenPuro shRNA Cloning and Expression Lentivector (CMV; System biosciences, SI505A-1) and sub-cloned into ITR-CAG-DEST-IRESNeomycin-ITR plasmid (generous gift from Marc Supprian Schmidt). ITR-CAG-DEST-IRES-NeomycinITR (control plasmid) (Supplementary Fig. S1a) or ITR-CAG-GFP-IRES-Neomycin-ITR (GFP plasmid) (Supplementary Fig. S1b) was mixed with SB100x transposes (1:1 ratio) and the mixture was transiently transfected into the cell line using Lipofectamine 2000 (Thermo Fisher Scientific, 11668027). Three days post-transfection, transfected cells were selected with $300 \mu \mathrm{g} / \mathrm{mL} \mathrm{G418}$ for 10 days. To validate the stable and constitutive expression of GFP, selected cells were analyzed by flow-cytometry. GFP-expressing Panc1 and HPNE were cultured in Iscove's Modified Dulbecco's Media (IMDM; GE Healthcare Hyclone, SH30228.01) supplemented with 5\% human serum (Innovative Research, IPLA-SER) and 1\% 1X Penicillin-Streptomycin (hereafter referred to as "cIMDM"). Cells were maintained in a humidified $\mathrm{CO}_{2}$ incubator at $37{ }^{\circ} \mathrm{C}$ and $5 \% \mathrm{CO}_{2}$.

\section{Multiplex array}

Conditioned media was generated from either the 2D culture of Panc1 and HPNE cells using a previously described method [55] or the 3D culture of these cell lines. Briefly, in the $2 \mathrm{D}$ culture, $1 \times 10^{6}$ cells were seeded in $30 \mathrm{~mL}$ of cIMDM in a T175 flask and allowed to grow to 70-80\% confluency. Media was then removed from the flasks, centrifuged for $10 \mathrm{~min}$ at $15000 \mathrm{rpm}$, sterile-filtered $(0.2 \mu \mathrm{m}$ pore size $)$ and stored at $-20{ }^{\circ} \mathrm{C}$ until use. For the 3D culture, cells were seeded at equal densities in the microfluidic device for at least $24 \mathrm{~h}$, before collecting media from all media reservoirs of each device. Cell media was centrifuged at $14000 \mathrm{rpm}$ for $10 \mathrm{~min}$ at $4{ }^{\circ} \mathrm{C}$ and the supernatant was stored in $-20^{\circ} \mathrm{C}$ until use. $2 \mathrm{D}$ and $3 \mathrm{D}$ culture media 
cytokines were respectively analyzed by the Proteome Profiler ${ }^{\mathrm{TM}}$ antibody array (R\&D Systems) and the Milliplex 38 Cytokine kit (Millipore, HCYTMAG-60K-PX38).

\section{Isolation of monocytes and differentiation into macrophages}

Blood samples and procedures used in this study have been approved by the Centralised Institutional Review Board, SingHealth (reference no: 2017/2512) and the Committee on the Use of Humans as Experimental Subjects (COUHES). All protocols are in accordance with The Code of Ethics of the World Medical Association. Written informed consent was given according to the principles expressed in the Declaration of Helsinki. Peripheral blood mononuclear cells (PBMCs) were isolated from whole blood of healthy donors by Ficoll-Paque (GE Healthcare, 17-1440-02) density gradient centrifugation, and monocytes were positively isolated using CD14 microbeads (Miltenyi Biotec, Auburn, CA). Monocytes were maintained in Petri dishes in cIMDM and $100 \mathrm{ng} / \mathrm{mL}$ recombinant human M-CSF (Immunotools, Friesoythe, Germany) over 7 days to generate macrophages. Cell viability was assessed by Trypan blue exclusion and was consistently $>90 \%$ viable.

\section{Fabrication of microfluidic device}

Microfluidic devices were fabricated following previously reported protocols [56,57]. Polydimethylsiloxane (PDMS; Sylgard 184 silicone elastomer kit, Dow Corning, Midland, MI, USA) were fabricated by standard soft lithography methods from a patterned SU-8 silicon wafer. Silicone elastomer and curing agent were mixed at a 10:1 weight ratio, degassed in a desiccator, poured onto the photolithographically patterned SU-8 structures and cured overnight at $37{ }^{\circ} \mathrm{C}$. Devices were cut from the PDMS replica, and inlet and outlet ports were created by biopsy punches before autoclave sterilization. After drying the devices overnight at $80{ }^{\circ} \mathrm{C}$, PDMS layers were plasma bonded to the glass cover slips to create channels of approximately $190 \mu \mathrm{m}$ in height. Each device consists of four connected channels (4.36 $\mathrm{mm}$ in length), with two for injecting hydrogels $(580 \mu \mathrm{m}$ wide $)$ and two for culture media (920 $\mu \mathrm{m}$ wide) 
(Fig. 1a). Each gel channel contains 9 trapezoidal structures (base lengths of $290 \mu \mathrm{m}$ and $120 \mu \mathrm{m}$, height of $140 \mu \mathrm{m})[33,55,56]$.

\section{Cell seeding}

All channels were coated with $1 \mathrm{mg} / \mathrm{mL}$ poly-D-lysine (PDL) solution (Sigma-Aldrich, St. Louis, MO) to prevent the detachment of collagen gels from the channel walls [43]. GFP-Panc1 were trypsinized, counted and resuspended in $2.5 \mathrm{mg} / \mathrm{mL}$ type I rat tail collagen gel (354236, Corning) solution. Macrophages were harvested by rinsing with D-PBS, incubating with PBS/EDTA (PBS; 2 mM EDTA; Axil Scientific, BUF1052) for $10-15 \mathrm{~min}$ at $37^{\circ} \mathrm{C}, 5 \% \mathrm{CO}_{2}$, before adding cIMDM and gently scraping. Harvested macrophages were fluorescently stained with $2 \mu \mathrm{M}$ Cell Tracker Orange, CMRA (Invitrogen) and resuspended separately in the same type of hydrogel. Cell seeding was performed using a protocol that was previously described $[33,55,56]$. Briefly, the GFP-Panc1 hydrogel suspension was injected into one gel channel and allowed to polymerize for $20 \mathrm{~min}$ in the incubator $\left(37^{\circ} \mathrm{C}, 5 \% \mathrm{CO}_{2}\right)$, followed by injection of the macrophage hydrogel suspension in the other gel channel and then gentle addition of cIMDM into the lateral fluidic channel adjacent to the GFP-Panc1 gel channel. The device was returned to the incubator for $40 \mathrm{~min}$ for the second injected hydrogel to polymerize before gentle addition of cIMDM to the media channel adjacent to the macrophage gel channel. In some devices, collagen hydrogel without GFP-Panc1 (herein referred to as "blank hydrogel") was used as the first hydrogel being injected (Fig. 1b and 1c). Devices containing cells were left to stabilize overnight in the incubator.

\section{D assay and quantification of macrophage migration}

After overnight incubation, the cell-containing PDMS chamber was sealed against another PDMS layer that contained a large media reservoir (Fig. 1a). To achieve a flow velocity of $\sim 3 \mu \mathrm{m} / \mathrm{s}$ through the 3D collagen hydrogel, a media-height difference of $2.5 \mathrm{~mm}$ was established at the inlet ports connecting the media reservoir with the channels containing GFP-Panc1 or blank hydrogel. Through this set-up, media flowed from the media reservoir, through the GFP-Panc1 cells (or blank hydrogel), and then finally to the 
macrophages. Darcy's law was used to calculate the required media-height difference across the gel channels (refer to 'Calculation and verification of interstitial flow'). In some devices, respective concentrations (ranging from $25 \mathrm{ng} / \mathrm{mL}$ to $100 \mathrm{ng} / \mathrm{mL}$ ) of recombinant human IL-8 (Biolegend, 715404) and/or recombinant human CCL2 (Peprotech, 300-04) reconstituted in cIMDM was added. In other devices, $0.4 \mu \mathrm{g} / \mathrm{mL}$ of anti-IL-8 antibody (R\&D, MAB208) and/or $1 \mu \mathrm{g} / \mathrm{mL}$ of anti-CCL2 antibody (R\&D, MAB279) was added.

Devices were transferred onto a confocal microscope (Olympus model FV1000) fit with a humidified environmental chamber which maintained a temperature of $37{ }^{\circ} \mathrm{C}$ and $5 \% \mathrm{CO}_{2}$. Macrophages were exposed for $24 \mathrm{~h}$ to the various stimuli, including IF, recombinant cytokines and anti-IL-8/anti-CCL2 antibodies, where their migration in 3D was tracked by time-lapse confocal microscopy, with 3D image stacks taken every $25 \mathrm{~min}$ at a $20 \mathrm{X}$ magnification $(800 \times 800$ pixel density $)$. As the cross-sectional area of the reservoirs was approximately 1500 times that of the hydrogel region, there was a negligible decrease in the mediaheight difference during the $24 \mathrm{~h}$ duration. IMARIS 9.2 was used to track and quantify the migration directedness and speed of macrophages in 3D and to produce the cell trajectory plots of macrophage migration.

\section{Calculation and verification of interstitial flow}

The hydraulic permeability, $K$, of the $2.5 \mathrm{mg} / \mathrm{mL}$ collagen gel used in this study was previously determined by Darcy's law to be $\sim 7 \times 10^{-14} \mathrm{~m}^{2}$ [51]. Darcy's law was also used to determine the media-height difference that was required to establish a desirable IF velocity, $v$, through the microfluidic device, as represented by Eq. 1:

$$
\Delta h=\frac{v \mu W}{K \rho g}
$$

where $\rho$ is the density and $\mu$ is the viscosity of cIMDM media, $W$ is the width of the chamber, and $\Delta h$ is the initial media-height difference of the reservoir [58]. Based on the geometry of the total hydrogel matrix in 
the microfluidic device and the estimated hydraulic permeability, a media-height difference of $2.5 \mathrm{~mm}$ was needed to generate an IF velocity of approximately $3 \mu \mathrm{m} / \mathrm{s}$ in the hydrogel.

To quantify and confirm the velocity of IF through the hydrogel at the start and end of the IF treatment, fluorescence recovery after photobleaching (FRAP) was used. Here, $100 \mu \mathrm{g} / \mathrm{mL}$ of $70 \mathrm{kDa}$ FITC-dextran in cIMDM was added and a spot of $30 \mu \mathrm{m}$ diameter of the hydrogel was bleached using the highest intensity of the laser, according to the microscope guidelines. After the bleaching step, time-lapse images in short intervals $(\sim 1.6 \mathrm{~s})$ were recorded to monitor the recovery in fluorescence. Photobleaching was performed for the hydrogels in both gel microchannels. ImageJ and Matlab was used to quantify the change in fluorescence after the bleaching step.

\section{Signaling network model construction}

A simplified version of the hypothesized signaling network model linking IL-8-based and CCL2-based signaling and IF-induced macrophage migration was constructed by analysing literature-established signaling pathways associated with each of these extracellular stimuli. Relevant networks were analyzed for intersections (which indicate the presence of key signaling species), and common regulators were used to combine and unify the networks into a single network. These common regulators were determined to be various members of Rho GTPases or regulatory signaling species associated with their activity. The similar trends exhibited by both macrophage migration directedness and speed also suggested a common regulator. Thus, we combined the downstream signaling activity of Rho GTPases into a single regulatory node that regulated both migration directedness and speed. Finally, we simplified the network branches by connecting each upstream stimulus with a common downstream migration regulator, removing all intermediate reactions. 


\section{Mathematical model development}

A mathematical model was constructed from the aforementioned hypothesized signaling network model. Specifically, an ordinary differential equation (ODE) model tracked the concentration of each signaling element in its active form and its interactions with other signaling elements [59,60]. The concentrations of activated receptors CXCR1/2 and CCR2 were defined in relation to the concentrations of their respective ligands IL-8 and CCL2 using steady state approximations and the ligand-receptor dissociation constant, $k_{d}$ (Eq. 2 and 3) [61]. The concentration of activated FAK in response to integrin-mediated, IF-induced signaling was calculated using a Hill function. Here, IF speed was correlated with the steady state concentration of activated FAK, and constants were calculated to reproduce in vitro experimental observations (Eq. 4) [51]. Next, the concentration of active G proteins dissociating from G protein-coupled receptors CXCR1/2 and CCR2 in response to IL-8 and CCL2 binding, respectively, was calculated by integrating the two receptor signals in an additive manner through Hill functions with corresponding dissociation constants $\left(k_{d}\right)$ (Eq. 6). Then, we calculated the concentration of active common regulator (Eq. 8). Here, the concentrations of IL-8, FAK, and CCL2 additively contributed to common regulator activation through Hill functions with corresponding dissociation constants $\left(k_{d}\right)$. Finally, migration directedness and speed were modelled as Hill functions that exhibit basal activity when no active common regulator is present and increase asymptotically to a maximum value as the concentration of active common regulator increases (Eq. 9 and 10). Table M1 defines the signaling species being tracked by the model. 
Table 1. Species variable abbreviations, definitions, initial steady state values and units.

\begin{tabular}{|c|c|l|c|c|}
\hline Species & Abbreviation & \multicolumn{1}{|c|}{ Definition } & Initial Value & Units \\
\hline $\mathrm{S}_{1}$ & IL-8 & Interleukin-8 & $9.01^{*}$ & $\mathrm{nM}$ \\
\hline $\mathrm{S}_{2}$ & CCL2 & Chemokine (CC motif) ligand 2 & $9.07^{*}$ & $\mathrm{nM}$ \\
\hline $\mathrm{S}_{3}$ & IF & Interstitial flow & 3000 & $\mathrm{~nm} / \mathrm{s}$ \\
\hline $\mathrm{S}_{4}$ & CXCR1/2 & $\begin{array}{l}\text { C-X-C motif chemokine receptor 1 or 2; } \\
\text { receptor for IL-8 }\end{array}$ & $\mathrm{nM}$ \\
\hline $\mathrm{S}_{5}$ & CCR2 & $\begin{array}{l}\text { C-C chemokine receptor type 2; receptor for } \\
\text { CCL2 }\end{array}$ & 0 & $\mathrm{nM}$ \\
\hline $\mathrm{S}_{6}$ & FAK & $\begin{array}{l}\text { Focal adhesion kinase; activated in response to } \\
\text { interstitial flow }\end{array}$ & 9.48 & $\mathrm{nM}$ \\
\hline $\mathrm{S}_{7}$ & G proteins & $\begin{array}{l}\text { Family of signaling G proteins (associated with } \\
\text { G-protein-coupled receptors CXCR1/2 and } \\
\text { CCR2) }\end{array}$ & 0 & $\mathrm{nM}$ \\
\hline $\mathrm{S}_{8}$ & $\begin{array}{l}\text { Common } \\
\text { regulator }\end{array}$ & $\begin{array}{l}\text { Downstream common regulator of migration } \\
\text { directedness and speed. Potentially one or more } \\
\text { Rho GTPases such as CDC42, Rac1 and/or } \\
\text { RhoA }\end{array}$ & 87.8 & $\mathrm{nM}$ \\
\hline $\mathrm{M}_{\mathrm{D}}$ & Directedness & Migration directedness relative to control & 1.00 & - \\
\hline $\mathrm{M}_{\mathrm{S}}$ & Speed & Migration speed relative to control & 1.00 & - \\
\hline
\end{tabular}

*Equivalent to $100 \mathrm{ng} / \mathrm{mL}$.

The mathematical modeling framework is as follows (Eq. $2-10$ ):

$$
\begin{aligned}
& S_{4}=\frac{S_{4, t o t} S_{1}}{k_{1}+S_{1}} \\
& S_{5}=\frac{S_{5, t o t} S_{2}}{k_{2}+S_{2}} \\
& S_{6}=b_{3}+\frac{\left(S_{6, t o t}-b_{3}\right) S_{3}}{k_{3}+S_{3}}, \quad \text { where } \quad k_{3}=S_{3, \text { data }}\left(\frac{S_{6, t o t}-b_{3}}{b_{3}(\delta-1)}-1\right) \\
& S_{7, i}=S_{7, t o t}-S_{7} \\
& \frac{d S_{7}}{d t}=S_{7, i}\left(\frac{p_{4} S_{4}^{n_{4}}}{k_{4}{ }^{n_{4}}+S_{4}{ }^{n_{4}}}+\frac{p_{5} S_{5}^{n_{5}}}{k_{5}{ }^{n_{5}+S_{5}{ }^{n_{5}}}}\right)-c_{7} S_{7} \\
& S_{8, i}=S_{8, t o t}-S_{8}
\end{aligned}
$$

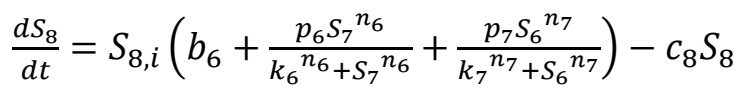




$$
\begin{aligned}
& M_{D}=1+\left(r_{D}-1\right) \frac{S_{8}{ }^{n_{D}}}{k_{D}{ }^{{ }^{D}+S_{8}{ }^{n} D}} \\
& M_{S}=1+\left(r_{S}-1\right) \frac{S_{8}{ }^{{ }}}{k_{S}{ }^{{ } S+S_{8}{ }^{n_{S}}}}
\end{aligned}
$$

To simulate experiments involving the treatment of macrophages with TSF, or co-culture with cancer cells without IF, the following relationship was used to simulate TSF composition (Eq. 11):

$$
[\mathrm{CCL} 2]_{T S F}=r_{T S F}[\mathrm{IL}-8]_{T S F}
$$

where [IL-8] $]_{T S F}$ and $r_{T S F}$ are free parameters fit to experimental data.

Furthermore, to simulate experiments where TSF-treated macrophages are exposed to anti-IL- 8 and/or antiCCL2 antibodies, the following functions were used to determine the uninhibited concentrations of each cytokine (Eq. 12 and 13):

$$
\begin{aligned}
{[\mathrm{IL}-8]_{\alpha} } & =[\mathrm{IL}-8]_{T S F}\left(\frac{k_{\alpha, I L 8}[\mathrm{LL}-8]_{T S F}}{\alpha_{I L 8}+k_{\alpha, I L 8}[\mathrm{IL}-8]_{T S F}}\right) \\
{[\mathrm{CCL} 2]_{\alpha} } & =[\mathrm{CCL} 2]_{T S F}\left(\frac{k_{\alpha, C C L 2}[\mathrm{CCL} 2]_{T S F}}{\alpha_{C C L 2}+k_{\alpha, C C L 2}[\mathrm{CCL} 2]_{T S F}}\right)
\end{aligned}
$$

\section{Model parameter estimation}

The mathematical model was implemented as a purpose-constructed code in Python 2.7 and solved at 50,000 time points over $48 \mathrm{~h}$ of simulated experimental time via the odeint solver found in the scipy.integrate module using the default settings. The model contained 37 parameters, 13 of which were assigned to experimentally-derived values taken from the literature (Table 2), 2 of which were assigned based on manufacturer provided protocols for antibody blockade, and 2 of which were directly calculated from in vitro directedness and speed data. Here, the kinetics of each upstream interaction between IL-8, CCL2 or IF speed with downstream signaling elements of the model were taken from the literature. Also, initial conditions of each parameter were determined by running the model without the stimuli until it reached steady state. In addition, the total concentration of each intermediate signaling species (assumed 
here to be the total concentration of each species at steady state, including both its active and inactive forms) was assigned to a known benchmark value from the literature. The remaining 20 free parameters were fit to our in vitro experimental results using a gradient descent least-squares error minimization approach that minimized the error function (Eq. 14):

$$
E=\sum_{i}\left(\frac{M_{D, i}-m_{D, i}}{s_{D, i}}\right)^{2}+\sum_{i}\left(\frac{M_{S, i}-m_{S, i}}{s_{S, i}}\right)^{2}
$$

where $M_{D, i}$ and $M_{S, i}$ are the simulated migration directedness and speed for each stimulus, respectively, $m_{D, i}$ and $m_{S, i}$ are the experimentally measured migration directedness and speed for each stimulus, respectively, with associated sample standard deviations $s_{D, i}$ and $s_{S, i}$, respectively. All free parameters were allowed to fit to any value, with the exception of the Hill coefficients $\left(n_{4}, n_{5}, n_{6}, n_{7}\right)$, which were limited to a maximum value of 4 . Table 2 shows the fit parameters generated from the model fitting process. Employing such a large number of free parameters proved necessary in order to achieve a sufficiently accurate fit that could capably capture the trends across all 58 experimental data points. We contend that this significant excess in the number of data points - as compared with the number of free parameters reduced the likelihood of overfitting in this case.

Table 2. Parameter values used in simulations. All activation rate constants, dissociation constants, hill coefficients, and basal activation constants are numbered such that they correspond to the reaction numbers indicated in Fig. 4. All total species concentrations and degradation rates are numbered such that they correspond to the species numbers indicated in Fig. 4 and detailed in Table 1.

\begin{tabular}{|c|c|c|l|c|}
\hline Parameter & Value & Units & \multicolumn{1}{|c|}{ Definition } & Source \\
\hline$p_{4}$ & $9.59 \times 10^{-5}$ & $1 / \mathrm{s} 1 / \mathrm{nM}$ & $\begin{array}{l}\text { Activation rate constant } \\
\text { for CXCR1/2 activating } \\
\text { G proteins }\end{array}$ & Fit to in vitro experimental data \\
\hline$p_{5}$ & $1.62 \times 10^{-4}$ & $1 / \mathrm{s} 1 / \mathrm{nM}$ & $\begin{array}{l}\text { Activation rate constant } \\
\text { for CCR2 activating } \mathrm{G} \\
\text { proteins }\end{array}$ & Fit to in vitro experimental data \\
\hline$p_{6}$ & $6.97 \times 10^{-3}$ & $1 / \mathrm{s} 1 / \mathrm{nM}$ & $\begin{array}{l}\text { Activation rate constant } \\
\text { for G proteins activating } \\
\text { common regulator }\end{array}$ & Fit to in vitro experimental data \\
\hline$p_{7}$ & $1.46 \times 10^{-3}$ & $1 / \mathrm{s} 1 / \mathrm{nM}$ & $\begin{array}{l}\text { Activation rate constant } \\
\text { for active FAK activating } \\
\text { common regulator }\end{array}$ & Fit to in vitro experimental data \\
\hline
\end{tabular}




\begin{tabular}{|c|c|c|c|c|}
\hline$k_{1}$ & 1.9 & $\mathrm{nM}$ & $\begin{array}{l}\text { Dissociation constant for } \\
\text { IL-8 binding to CXCR } 1 / 2\end{array}$ & {$[62]$} \\
\hline$k_{2}$ & 0.77 & $\mathrm{nM}$ & $\begin{array}{l}\text { Dissociation constant for } \\
\text { CCL2 binding to CCR2 }\end{array}$ & [63] \\
\hline$k_{4}$ & 1030 & $\mathrm{nM}$ & $\begin{array}{l}\text { Apparent dissociation } \\
\text { constant for active } \\
\text { CXCR } 1 / 2 \text { activating G } \\
\text { proteins }\end{array}$ & Fit to in vitro experimental data \\
\hline$k_{5}$ & 739 & $\mathrm{nM}$ & $\begin{array}{l}\text { Apparent dissociation } \\
\text { constant for active CCR2 } \\
\text { activating } \mathrm{G} \text { proteins }\end{array}$ & Fit to in vitro experimental data \\
\hline$k_{6}$ & 182 & $\mathrm{nM}$ & $\begin{array}{l}\text { Apparent dissociation } \\
\text { constant for } G \text { proteins } \\
\text { activating common } \\
\text { regulator }\end{array}$ & Fit to in vitro experimental data \\
\hline$k_{7}$ & 183 & $\mathrm{nM}$ & $\begin{array}{l}\text { Apparent dissociation } \\
\text { constant for active FAK } \\
\text { activating common } \\
\text { regulator }\end{array}$ & Fit to in vitro experimental data \\
\hline$n_{4}$ & 1.40 & - & $\begin{array}{l}\text { Hill coefficient for active } \\
\text { CXCR } 1 / 2 \text { activating } G \\
\text { proteins }\end{array}$ & Fit to in vitro experimental data \\
\hline$n_{5}$ & 3.42 & - & $\begin{array}{l}\text { Hill coefficient for active } \\
\text { CCR } 2 \text { activating } G \\
\text { proteins }\end{array}$ & Fit to in vitro experimental data \\
\hline$n_{6}$ & 4.0 & - & $\begin{array}{l}\text { Hill coefficient for } \mathrm{G} \\
\text { proteins activating } \\
\text { common regulator }\end{array}$ & Fit to in vitro experimental data \\
\hline$n_{7}$ & 1.40 & - & $\begin{array}{l}\text { Hill coefficient for active } \\
\text { FAK activating common } \\
\text { regulator }\end{array}$ & Fit to in vitro experimental data \\
\hline$b_{3}$ & 9.48 & $\mathrm{nM}$ & $\begin{array}{l}\text { Basal concentration of } \\
\text { active FAK }\end{array}$ & Fit to in vitro experimental data \\
\hline$b_{6}$ & $1.05 \times 10^{-5}$ & $1 / \mathrm{s}$ & $\begin{array}{l}\text { Basal rate of common } \\
\text { regulator activation }\end{array}$ & Fit to in vitro experimental data \\
\hline$S_{4, t o t}$ & 500 & $\mathrm{nM}$ & $\begin{array}{l}\text { Total concentration of } \\
\text { active and inactive } \\
\text { CXCR } 1 / 2\end{array}$ & {$[64]$} \\
\hline$S_{5, t o t}$ & 500 & $\mathrm{nM}$ & $\begin{array}{l}\text { Total concentration of } \\
\text { active and inactive CCR2 }\end{array}$ & {$[64]$} \\
\hline$S_{6, t o t}$ & 500 & $\mathrm{nM}$ & $\begin{array}{l}\text { Total concentration of } \\
\text { active and inactive FAK }\end{array}$ & {$[64]$} \\
\hline$S_{7, t o t}$ & 500 & $\mathrm{nM}$ & $\begin{array}{l}\text { Total concentration of } \\
\text { active and inactive } G \\
\text { proteins }\end{array}$ & {$[64]$} \\
\hline$S_{8, t o t}$ & 500 & $\mathrm{nM}$ & $\begin{array}{l}\text { Total concentration of } \\
\text { active and inactive } \\
\text { common regulator }\end{array}$ & [64] \\
\hline
\end{tabular}




\begin{tabular}{|c|c|c|c|c|}
\hline$c_{7}$ & $1.56 \times 10^{-4}$ & $1 / \mathrm{s}$ & $\begin{array}{l}\text { Combined degradation } \\
\text { and dilution rate for } G \\
\text { proteins }\end{array}$ & {$[65]$} \\
\hline$c_{8}$ & $1.56 \times 10^{-4}$ & $1 / \mathrm{s}$ & $\begin{array}{l}\text { Combined degradation } \\
\text { and dilution rate for } \\
\text { common regulator }\end{array}$ & {$[65]$} \\
\hline$S_{3, \text { data }}$ & $3.00 \times 10^{3}$ & $\mathrm{~nm} / \mathrm{s}$ & $\begin{array}{l}\text { Interstitial flow (IF) speed } \\
\text { associated with } \delta \text {-fold } \\
\text { increased FAK activation }\end{array}$ & [48] \\
\hline$\delta$ & 3.28 & - & $\begin{array}{l}\text { Fold increase in FAK } \\
\text { activation associated with } \\
\text { IF at } S_{2, \text { data }} \mathrm{nm} / \mathrm{s}\end{array}$ & {$[48]$} \\
\hline$r_{S}$ & 3.25 & - & $\begin{array}{l}\text { Ratio between highest } \\
\text { and lowest observed } \\
\text { migration speed }\end{array}$ & $\begin{array}{l}\text { Calculated from in vitro } \\
\text { experimental data }\end{array}$ \\
\hline$k_{S}$ & 202 & $\mathrm{nM}$ & $\begin{array}{l}\text { Half maximum constant } \\
\text { for common regulator- } \\
\text { induced migration speed }\end{array}$ & Fit to in vitro experimental data \\
\hline$n_{S}$ & 3.87 & - & $\begin{array}{l}\text { Hill coefficient for } \\
\text { common regulator- } \\
\text { induced migration speed }\end{array}$ & Fit to in vitro experimental data \\
\hline$r_{D}$ & 2.95 & - & $\begin{array}{l}\text { Ratio between highest } \\
\text { and lowest observed } \\
\text { migration directedness }\end{array}$ & $\begin{array}{l}\text { Calculated from in vitro } \\
\text { experimental data }\end{array}$ \\
\hline$k_{D}$ & 120 & $\mathrm{nM}$ & $\begin{array}{l}\text { Half maximum constant } \\
\text { for common regulator- } \\
\text { induced migration } \\
\text { directedness }\end{array}$ & Fit to in vitro experimental data \\
\hline$n_{D}$ & 3.64 & - & $\begin{array}{l}\text { Hill coefficient for } \\
\text { common regulator- } \\
\text { induced migration } \\
\text { directedness }\end{array}$ & Fit to in vitro experimental data \\
\hline$[\mathrm{IL}-8]_{T S F}$ & 0.167 & $\mathrm{nM}$ & - & Fit to in vitro experimental data \\
\hline$r_{T S F}$ & 1.18 & - & - & Fit to in vitro experimental data \\
\hline$\alpha_{I L 8}$ & 2.67 & $\mathrm{nM}$ & $\begin{array}{l}\text { Concentration of anti-IL- } \\
8 \text { antibody in antibody } \\
\text { blockade experiments }\end{array}$ & $\begin{array}{l}\text { Reflective of in vitro experimental } \\
\text { conditions }\end{array}$ \\
\hline$k_{\alpha, I L 8}$ & 0.888 & - & $\begin{array}{l}\text { Molar ratio of antibody to } \\
\text { IL- } 8 \text { required for } 50 \% \\
\text { inhibition }\end{array}$ & $\begin{array}{l}\text { Based on manufacturer supplied } \\
\text { datasheet }\end{array}$ \\
\hline$\alpha_{C C L 2}$ & 6.67 & $\mathrm{nM}$ & $\begin{array}{l}\text { Concentration of anti- } \\
\text { CCL2 antibody in } \\
\text { antibody blockade } \\
\text { experiments }\end{array}$ & $\begin{array}{c}\text { Reflective of in vitro experimental } \\
\text { conditions }\end{array}$ \\
\hline$k_{\alpha, C C L 2}$ & 1.32 & - & $\begin{array}{l}\text { Molar ratio of antibody to } \\
\text { CCL2 required for } 50 \% \\
\text { inhibition }\end{array}$ & $\begin{array}{l}\text { Based on manufacturer supplied } \\
\text { datasheet }\end{array}$ \\
\hline
\end{tabular}




\section{Sensitivity analysis}

Stimulus sensitivity analysis was used to quantify the effect of each extracellular stimulus on the concentration of active common regulator. Here, the elasticity of the concentration of active common regulator was computed for the concentration of each stimulus using the following function (Eq. 15):

$$
\phi_{C, X}=\frac{\Delta \%[\text { Common Regulator }]}{\Delta \% X}
$$

where the denominator represents a $20 \%$ change in the stimulus under study (centred at the default stimulus value given in Table 1) and the numerator represents the percent change in the concentration of active common regulator.

An additional stimulus sensitivity analysis was used to quantify the effect of each extracellular stimulus on the quality of the model fit against the in vitro experimental data. Here, the model $R^{2}$ elasticity was computed for each stimulus using the following function (Eq. 16):

$$
\phi_{R, X}=\frac{\Delta \% R^{2}}{\Delta \% X}
$$

where the denominator represents a $20 \%$ change in the stimulus under study (centred at the default stimulus value given in Table 1) and the numerator represents the percent change in the $R^{2}$ value between the model outputs and all in vitro experimental directedness and speed data.

Parameter sensitivity analysis was used to quantify the effect of each model parameter on the concentration of active common regulator. Here, the elasticity of the concentration of active common regulator was computed for each parameter using the following function (Eq. 17):

$$
\phi_{C, P}=\frac{\Delta \%[\text { Common Regulator }]}{\Delta \% P}
$$

where the denominator represents a $20 \%$ change in the parameter under study (centred at the default parameter value given in Table 2) and the numerator represents the percent change in the concentration of active common regulator. 
Finally, an additional parameter sensitivity analysis was used to quantify the effect of each model parameter on the quality of the model fit against in vitro experimental data. Here, the model $R^{2}$ elasticity was computed for each parameter using the following function (Eq. 18):

$$
\phi_{R, P}=\frac{\Delta \% R^{2}}{\Delta \% P}
$$

where the denominator represents a $20 \%$ change in the parameter under study (centred at the default parameter value given in Table 2), and the numerator represents the percent change in the $R^{2}$ value between the model outputs and all in vitro experimental directedness and speed data.

\section{Statistical analysis}

Statistical analysis of experimental data was performed using GraphPad Prism 8.2 (GraphPad Software) considering at least two regions of interest (ROI) in the hydrogel per device. For each in vitro experiment, the average migration directedness and speed of macrophages in each ROI ( 150 macrophages per ROI) was used to generate a data point. To quantify the agreement between the in vitro experimental data and the output values of the mathematical model, the $R^{2}$ values were calculated for (1) directedness data only, (2) speed data only, and (3) all data together. At each data point, statistical analysis was performed to determine if the population mean predicted by the model would be likely to produce the in vitro experimental data. Data were plotted as the mean \pm standard error of the mean (SEM), where n.s. represents not significant, * represents $P \leq 0.05$, ** represents $P \leq 0.01$, *** represents $P \leq 0.001$ and **** represents $P \leq 0.0001$. Statistical significance was determined using a Student's $t$-test or where appropriate, a one-way ANOVA with Holm-Sidak's multiple comparisons test. Only a $P$-value or adjusted $P$-value of $\leq 0.05$ was taken as evidence of statistical significance. 


\section{RESULTS}

\section{Generation of an in vitro 3D co-culture model with tumor interstitial flow}

Based on previously optimized protocols [51,56], we designed a 3D in vitro microfluidic model of tumor IF to specifically study macrophage migration. In this platform, we cultured tumor cells in one channel and macrophages in the adjacent channel, thus allowing us to simulate and study the impact of tumor-originating IF on macrophage migration without the influence of physical cell contact (Fig. 1). In our set-up, we confirmed that the velocity of IF through both gel channels was within the range reported for tumor tissues $[25,26]$. Fluorescence recovery after photobleaching (FRAP) analysis revealed a mean IF velocity of $3.9 \pm$ $0.7 \mu \mathrm{m} / \mathrm{s}$ at the beginning of IF exposure and $4.4 \pm 0.5 \mu \mathrm{m} / \mathrm{s}$ after $24 \mathrm{~h}(P>0.05)$ (Supplementary Fig. S3). These results correspond with the height difference of $2.5 \mathrm{~mm}$ between the two media channels which stayed relatively unchanged over the $24 \mathrm{~h}$. Thus, it could be assumed that IF velocity was relatively constant throughout the duration of IF treatment.

\section{Similar effect on macrophage migration by tumor-secreted factors and interstitial flow}

In our first set of in vitro experiments, we observed that compared to the control macrophage monoculture without IF (Fig. 2ai), $24 \mathrm{~h}$ of IF exposure appeared to increase macrophage motility (Fig. 2aii) as shown by the relatively increased spread of their $x-y$ migration path trajectories. Interestingly, it appeared that the presence of tumor cells alone without IF (TSF) also increased the spread of migration path trajectories relatively (Fig. 2aiii), suggesting that either IF or TSF alone could promote increased macrophage motility. Interestingly, combining IF and TSF (at the cell concentrations tested in Fig. 2) did not have an additive effect on the spread of macrophage migration (Fig. 2aiv).

To ascertain the effect of each stimulus on macrophage motility, we quantified the directedness and speed of macrophage migration during the period of IF exposure following a previously reported approach (Fig. 2b) [36,51]. Consistent with the observed increase in $x-y$ migration path trajectories, IF, TSF or the combination of both could substantially increase the directedness (Fig. 2c) and speed of macrophage 
migration (Fig. 2d). Compared to the untreated control where the directedness and speed of macrophage migration was $\mathrm{D}=0.31 \pm 0.04$ and $\mathrm{S}=8.3 \pm 1.2 \mu \mathrm{m} / \mathrm{h}$, respectively, a 2-fold increase in directedness and 3-fold increase in speed was observed for the conditions of IF ( $D=0.57 \pm 0.03, S=19 \pm 3 \mu \mathrm{m} / \mathrm{h}$ ), TSF (D $=0.63 \pm 0.04, S=23 \pm 3 \mu \mathrm{m} / \mathrm{h})$ and the IF-TSF combination $(\mathrm{D}=0.62 \pm 0.06, \mathrm{~S}=24 \pm 3 \mu \mathrm{m} / \mathrm{h})$, and these values are within the range reported in previous in vitro investigations [51].

\section{Hypothesized signaling pathway linking key tumor-secreted factors and Rho GTPase-regulated migration}

A multiplex cytokine array of culture supernatant of the tumor cell line (Panc1) and a normal control cell line (HPNE) was conducted to identify the main cytokines within TSF that drove the migration behaviour that we observed in vitro of macrophages. Our analysis on 2D cell culture-derived supernatant revealed several cytokines secreted at higher levels by the Panc1 compared to the HPNE cell line (Fig. 3a). A review of known signaling networks revealed that the upregulation of CCL2 and IL-8 is highly associated with the regulation of cell migration [66,67]. We also confirmed that Panc1 secreted higher levels of both cytokines than HPNE in the 3D in vitro culture environment (Fig. 3b), suggesting that IL-8 and CCL2 could mainly drive the migration we observed of macrophages in the $3 \mathrm{D}$ in vitro system.

Mechanistically, IL-8 $[66,68,69]$ and CCL2 $[67,70-73]$ bind to G protein-coupled receptors CXCR1/2 and CCR2, respectively, resulting in the activation and subsequent dissociation of an associated G protein [74]. This releases the $\alpha$ subunit of the $G$ protein to activate further intracellular signaling that results in the posttranslational regulation of regulatory proteins such as small monomeric GTPases of the Rho-family, leading to polymerization and retraction of the actin cytoskeleton which are important processes for cells to migrate. Additionally, our in vitro experimental data support previous studies that have demonstrated a synergistic integration between these receptors, whereby downstream signals are significantly greater in response to the activation of both receptors than either receptor alone [75]. This synergy has been shown to depend on the activation of both receptors, suggesting that synergy is the result of intracellular signaling, as opposed to extracellular cytokine interactions or receptor-receptor associations [75]. Moreover, even in the presence 
of both receptors, certain cell types fail to demonstrate this synergy, suggesting this behaviour arises from a characteristic intracellular signaling motif or protein that is unique to certain cell types such as macrophages [76]. G proteins represent a common element in the downstream signaling networks associated with both receptors [68,73], and are upstream of migration-regulating Rho GTPases and extracellular signal-regulated kinases (ERK) (which also exhibit a synergistic activation in response to the activation of both receptors) [75]. Thus, we hypothesized that a subset of G proteins may represent the integration point and the source of the synergy between these signaling pathways. In addition, IF-modulated signaling, as mediated by integrin- $\beta 2$ and FAK, is known to drive the activation and downstream migratory activity associated with Rho GTPases [51,77]. Finally, because our in vitro experimental data show that IF and TSF induced a similar increase in directedness and speed, we hypothesized that IL-8, CCL2 and IF regulate one or more of the relevant Rho GTPases, namely CDC42, Rac1 and/or RhoA [38-40].

Notably, the purpose of our model is to infer the logical structure of the network that integrates multiple molecular (IL-8 and CCL2) and mechanical (IF) stimuli, but not the intricate details of interactions associated with the downstream Rho GTPases. For this reason, we model the Rho GTPases collectively through a single representative concentration, and hereafter denote this group of signaling species collectively as "common regulator". Also, as downstream signaling (connecting Rho GTPase activity to migration-related processes) becomes increasingly complex, we recognize that there is no need to model all theoretical details of GTPases signaling. Moreover, the similar trends exhibited by both directedness and speed in response to all tested stimuli could be explained simply by a common regulator, as opposed to more complex interactions between largely independent signaling pathways. Thus, we depicted directedness and speed as phenomena that are indirectly induced by this common regulator, with intermediate signaling described by respective response functions that depend on the concentration of active common regulator. These considerations led to our proposed signaling network model (Fig. 4) [37]. 


\section{Effect of varying IL-8, CCL2 and/or interstitial flow on macrophage migration}

A second set of in vitro experiments were conducted to confirm the central roles of IL-8 and CCL2, and to also validate the proposed signaling network model. Compared to the non-treated control, where macrophage migration directedness and speed were $\mathrm{D}=0.35 \pm 0.06$ and $\mathrm{S}=8.4 \pm 1.1 \mu \mathrm{m} / \mathrm{h}$, respectively, the exogenous addition of saturating concentrations $(100 \mathrm{ng} / \mathrm{mL})$ of only $\mathrm{IL}-8(\mathrm{D}=0.56 \pm 0.03, \mathrm{~S}=20 \pm 2$ $\mu \mathrm{m} / \mathrm{h}$ ) or only CCL2 $(\mathrm{D}=0.60 \pm 0.07, \mathrm{~S}=22 \pm 4 \mu \mathrm{m} / \mathrm{h})$ to a macrophage monoculture substantially increased migration directedness and speed (Fig. 5a). These increases were comparable to those obtained by exposing the macrophage monoculture to only IF ( $D=0.61 \pm 0.05, S=23 \pm 4 \mu \mathrm{m} / \mathrm{h})$. Moreover, simultaneously exposing macrophages to IF together with either IL-8 (D = 0.59 $\pm 0.01, \mathrm{~S}=19 \pm 4 \mu \mathrm{m} / \mathrm{h})$ or CCL2 $(\mathrm{D}=0.60 \pm 0.08, \mathrm{~S}=22 \pm 3 \mu \mathrm{m} / \mathrm{h}$ ) did not further increase macrophage migration (Fig. 5a), supporting the notion that IF and TSF can commonly regulate macrophage migration behaviour.

Next, macrophages were exposed to sub-optimal concentrations of IL-8 and/or CCL2 to test if the same extent of increase in directedness and speed would be achieved as seen with either (1) a saturating concentration of individual cytokines, or (2) the 3D co-culture of macrophages and tumor cells (TSF). Suboptimal concentrations of $25 \mathrm{ng} / \mathrm{mL}$ of IL-8 and $25 \mathrm{ng} / \mathrm{mL}$ of CCL2 were identified based on prior titration experiments (Supplementary Fig. S2a and S2b). While exposure to the sub-optimal concentration of only IL-8 $(\mathrm{D}=0.34 \pm 0.03, \mathrm{~S}=9.9 \pm 1.3 \mu \mathrm{m} / \mathrm{h})$ or only CCL2 $(\mathrm{D}=0.35 \pm 0.08, \mathrm{~S}=11 \pm 2 \mu \mathrm{m} / \mathrm{h})$ did not result in an observable increase in directedness and speed, the combined exposure to sub-optimal concentrations of both cytokines promoted a comparable increase in directedness and speed $(\mathrm{D}=0.54 \pm 0.09, \mathrm{~S}=21 \pm 3$ $\mu \mathrm{m} / \mathrm{h}$ ) to the TSF condition ( $\mathrm{D}=0.6 \pm 0.1, \mathrm{~S}=22 \pm 2 \mu \mathrm{m} / \mathrm{h}$ ) (Fig. $5 \mathrm{~b}$ ). Importantly, the data suggest a synergistic integration of the intracellular signals associated with these two cytokines.

Finally, the introduction of $0.4 \mu \mathrm{g} / \mathrm{mL}$ of anti-IL-8 and $1 \mu \mathrm{g} / \mathrm{mL}$ of anti-CCL2 blocking antibodies could inhibit the TSF-mediated increase in migration directedness and speed (Fig. 5c). Compared to the co-culture condition $(\mathrm{TSF})(\mathrm{D}=0.56 \pm 0.10, \mathrm{~S}=25 \pm 2 \mu \mathrm{m} / \mathrm{h})$, both directedness and speed were substantially decreased upon treatment with anti-IL-8 $(\mathrm{D}=0.35 \pm 0.07, \mathrm{~S}=13.0 \pm 0.3 \mu \mathrm{m} / \mathrm{h})$, anti-CCL2 $(\mathrm{D}=0.33 \pm$ 
$0.06, \mathrm{~S}=13 \pm 1 \mu \mathrm{m} / \mathrm{h})$ or combinational blockade of both cytokines $(\mathrm{D}=0.27 \pm 0.02, \mathrm{~S}=11 \pm 1 \mu \mathrm{m} / \mathrm{h})$. Interestingly, IF could restore migration back to a level that was comparable to the TSF condition $(\mathrm{D}=0.47$ $\pm 0.09, \mathrm{~S}=21 \pm 2 \mu \mathrm{m} / \mathrm{h}$ ) despite combinational antibody blockade of IL-8 and CCL2.

\section{Modelled signaling network reproduces fundamental migration behaviors}

A mathematical model was developed based on the hypothesized signaling network (Fig. 4) using wellestablished systems biology modeling techniques, in particular the use of Hill functions (1) to relate the concentration of active signaling proteins with the rate of activation of their downstream targets, and (2) to determine the steady state concentrations of bound, active cytokine receptors using dissociation constants from the literature $[59,60]$. Here, an ODE model tracked the concentration of each signaling element in its active form and its interactions with other signaling elements. The system successfully replicated the experimental trends observed in Fig. 5a of migration directedness and speed (Fig. 6a). Importantly, the addition of individual or combined stimuli increased directedness and speed to approximately its maximum value, similar to in vitro observations. Also, the mathematical model could replicate in vitro experimentally observed migration responses to sub-optimal concentrations of IL-8 and/or CCL2 (Fig. 6b), to the antibody blockade of IL-8 and/or CCL2 when tumor cells were present (Fig. 6c), and to the titration of either cytokine concentration in the absence of IF (Supplementary Fig. S2c and S2d). Quantifying model agreement across all data points yields a mean coefficient of determination $\left(R^{2}\right)$ value of 0.70 for all directedness data, 0.90 for all speed data, and 0.83 for all directedness and speed data taken together. Therefore, our model could successfully reproduce $83 \%$ of the variation in the in vitro experimental data. Additionally, statistical analysis at each data point confirmed a pointwise agreement between in vitro experimentally observed and model-generated data, with no substantial difference between the two data types. 


\section{Sensitivity analysis reveals most influential stimuli and parameters}

Sensitivity analyses were conducted to identify the most influential stimuli and parameters that impacted macrophage migration behaviour. Because directedness and speed were both regulated by the common regulator, these analyses captured the influence of each parameter on both types of migration behaviors. First, we performed a stimulus sensitivity analysis to quantify the relative influence of each modelled stimulus on the concentration of active common regulator (Eq. 15) (Fig. 7a). IF had the greatest influence on the concentration of active common regulator, with approximately 1.5 times the influence of IL-8 and over 3 times that of CCL2.

Then, a stimulus sensitivity analysis focusing on the $R^{2}$ value was conducted to quantify the effect of varying the magnitude of each stimulus on the degree of agreement between the model and in vitro experimental data (Eq. 16) (Fig. 7b). This was done in order to determine the influence of each stimulus on the trends in directedness and speed across different stimuli as opposed to the concentration of active common regulator (which determines the magnitudes of directedness and speed). The influence of CCL2 on the $R^{2}$ value was much greater than that of IF, which itself was greater than that of IL- 8 . This analysis suggests that while IF had the greatest influence on the concentration of active common regulator, CCL2 had the dominant influence on the trends in directedness and speed across different stimuli. Taken together, the considerable difference in the influence of the three modelled extracellular stimuli suggests that each plays a different role in the regulation of the downstream directedness and speed signals.

Focusing on the kinetics of individual reactions, a parameter sensitivity analysis was conducted to analyze how a change in a parameter affected the concentration of active common regulator (Eq. 17) (Fig. 7c). Additionally, parameters were classified according to their associated signaling protein or motif to assess the influence of reactions associated with each network element on the overall downstream effect. Results revealed that parameters associated with $\mathrm{G}$ protein activation and turnover were in general the most influential, with particular influence attributed to parameters governing CCL2-induced G protein activation ( $k_{5}$ and $n_{5}$ ). Other highly influential parameters included $S_{5, t o t}$, which dictates the total concentration of 
CCL2 receptor CCR2, and two parameters associated with common regulator activation in response to CCL2 signaling $\left(n_{6}\right.$ and $\left.k_{6}\right)$. Overall, this analysis suggests an important role for CCL2 signaling, in particular, and G-protein mediated signals, in general, in the regulation of the common regulator and thus migration directedness and speed.

A second parameter sensitivity analysis was conducted to quantify how varying the magnitude of each parameter changed the $R^{2}$ value between the in vitro experimental data and model outputs (Eq. 18) (Fig. 7d). This analysis sought to determine the influence of each parameter on the trends in directedness and speed across different stimuli as opposed to the concentration of active common regulator. Again, parameters were classified according to their associated signaling protein or motif. The most influential parameter was $S_{5, t o t}$ Parameters associated with G protein activity were also among the most influential parameters, including $k_{5}$ (the second most influential parameter) which partially governs the rate of CCL2induced $G$ protein activation. Other highly influential parameters included those associated with the activation and turnover of the common regulator and the speed response to common regulator activity. Among the least influential parameters were those associated with the directedness response to common regulator activity. Overall, this analysis suggests that $G$ protein signaling, particularly that induced by CCL2, also plays a dominant role in determining the trends across different stimuli and thus the agreement between in vitro experimental data and model-generated outputs.

\section{DISCUSSION}

IF is an important tumor-associated biophysical factor that contributes toward cancer progression and poor patient survival [1,11-14]. Recent evidence suggests that IF also promotes the pro-tumor M2-polarization and migration activity of macrophages [51]. Moreover, clinical data demonstrate that macrophage density strongly correlates with increased metastasis [27]. Such findings suggest a plausible link between IF, macrophage activity (including their migration) and cancer metastasis, a research area that has not been 
widely studied [27]. In addition, macrophage migration is driven by tumor-secreted cytokines [36-40], which suggests that IF could act jointly with biochemical cues to affect macrophage migration. In this study, we demonstrate, for the first time, that IF can act in concert with tumor-secreted cytokines or factors (TSF) to regulate macrophage migration through a 3D in vitro TME-related ECM.

Previously, Li et al. observed that IF-exposed mouse macrophages migrated faster than non-treated control macrophages [51]. Following their work, we were interested to explore the results generated using a coculture set-up of tumor cells and human primary macrophages, which more closely resembles the dynamic exchange between these cell types in the in vivo human TME. Using a two-gel channel set-up with tumor cells and macrophages in co-culture in adjacent but separate channels, we could delineate between the effects of TSF and tumor-originating IF on macrophage migration. We observed that IF-exposed macrophages migrated faster and with increased directedness than non-treated controls which agrees with Li et al.'s work. To our knowledge, our model is the first co-culture system that investigates the role of tumor IF on immune cell migration.

The Panc1 cell line was used to create the in vitro co-culture IF system. Panc1 originates from PDAC which clinically represents one of the most malignant of cancers with one of the highest death rates [78,79]. PDAC metastasis correlates with a high macrophage infiltrate [55,80-84]. There are also numerous reports of cytokines underlying PDAC's aggressive biology [85-88]. Therefore, PDAC seemed an appropriate cancer-immune model for investigating the effect of macrophage migration in response to PDAC-specific TSF, where the effect of IF can additionally be assessed. Also, our study integrated in silico and in vitro methods, an approach that has been highly effective in deriving insight into cell migration mechanisms [8992]. Specifically, we demonstrated that by simulating in vitro conditions, an in silico signaling network model could be obtained associating key TSF (specifically IL-8 and CCL2), IF and macrophage migration. In turn, the in silico model was validated in vitro by adding different concentrations of exogenous IL8/CCL2 or blocking antibodies against these cytokines and evaluating macrophage migration. 
In our study, we first observed that the exposure of macrophages to IF or TSF induced a comparable increase in their migration directedness and speed. Interestingly, the non-additive effect of combining IF and TSF suggests that both IF and TSF could commonly regulate downstream macrophage migration when these stimuli are at saturating levels. Then, through a multiplex cytokine array of tumor-conditioned media, we identified IL-8 and CCL2 as the most probable cytokines driving the migration activity that we observed in the 3D in vitro system. In PDAC, acquisition of IL-8 and its receptors CXCR1 and CXCR2 on tumor cells $[93,94]$ and macrophages [95,96] correlates with tumor invasion [97-99] and the metastatic potential of solid tumors in murine models [100-105] and patients [106,107]. Similar to IL-8, the secretion of CCL2 and macrophage expression of its receptor CCR2 has been observed in the tumor tissues of patients with advanced metastasis [108-114]. Moreover, CCR2 blockade in a PDAC mouse model could deplete macrophages from the primary tumor to reduce metastasis [115]. Therefore, we focused on IL-8 and CCL2 in our study by virtue of their important role in regulating macrophage migration and PDAC metastasis. Notably, because IL-8/CCL2 are also implicated in the biology of other cancer types [42,116,117], our present findings can also be generalized to other cancers.

To understand the migration mechanism underlying our in vitro observations, we developed an in silico signaling network model to associate IL-8, CCL2, IF and macrophage migration. To develop this model, we first referenced key literature describing the intracellular signaling pathways associated with IL-8 and CCL2 [38-40], and studies concerning IF-induced cell migration mechanisms based on these cytokines $[51,77,118]$. Our findings show that IL-8 $[66,68,69]$ and CCL2 $[73,119]$ activate signaling that results in the post-translational regulation of small monomeric GTPases of the Rho-family, leading to macrophage migration through the polymerization and retraction of the actin cytoskeleton. Specifically, in CCL2 signaling, extracellular chemokine CCL2 binds to and activates the chemokine receptor CCR2 expressed on the cell membranes of macrophages. Subsequently, the C-terminal intracellular domain of CCR2 activates intracellular signaling proteins, including phosphatidylinositol-3-kinase (PI3K), which eventually results in the activation of various Rho GTPases, in particular Rac, regulating cytoskeletal reorganization 
and cell migration $[67,70-72,119]$. In the case of IL-8 signaling, extracellular chemokine IL-8 binds to and activates receptor $\mathrm{CXCR} 1 / 2$, activating heterotrimeric small G-proteins, $\mathrm{G}(\alpha, \beta, \gamma)$, which then promote the activation of Rho GTPases. Notably, other signaling activity downstream of CXCR1/2 and $\mathrm{G}(\alpha, \beta, \gamma)$ also activates PI3K and FAK.

In addition, IF triggers a process known as outside-in signaling where it engages multiple extracellular signals to activate cell membrane-bound integrins that then initiate intracellular cytoplasmic signaling [118]. These extracellular signals include the binding of integrins to respective ligands in the ECM, and various mechanical forces originating from IF including fluid shear stresses. Specifically, each stimuli induces a conformational change in integrin, activating the cytoplasmic signaling element of the protein and allowing it to interact with other signaling molecules involved in intracellular signaling cascades [118]. Additionally, the activation of integrin activates FAK and Src, stimulating Rho GTPases which drive macrophage cytoskeletal reorganization and migration [51,77]. Based on these findings, we hypothesized that IL-8, CCL2 and IF commonly regulate a group of Rho GTPases, including CDC42, Rac1 and/or RhoA [38-40], and this regulates macrophage migration. Additionally, the similar trends exhibited by both directedness and speed in response to all tested stimuli could be explained simply by a common regulator, as opposed to more complex interactions between largely independent signaling pathways. Finally, any attempt to fully model the highly complex signaling associated with migration regulation (that is downstream of this common signaling point) might greatly complicate the model with no added insight about how these signals are integrated. Thus, we depicted directedness and speed as phenomena indirectly induced by this common regulator, with intermediate signaling described by respective response functions that depend on the concentration of active common regulator.

To further validate our proposed model, we conducted a number of simulations and model analyses. We first demonstrated that the model was capable of reproducing the same trends of directedness and speed that we observed in vitro in response to the exposure to various combinations of IL-8, CCL2 and IF. Quantifying this agreement by calculating the $R^{2}$ value across all modelled directedness and speed data, we 
determined that the model successfully accounts for over $83 \%$ of the variation in the experimental data. Additional Student's $t$-tests further confirm the reproducibility of the model as there was no substantial difference between the model's predicted values and in vitro measurements at a point-by-point level. In line with in vitro experimentally observed macrophage migration behaviors, our model also displayed an OR gate-like behavior, where the exposure to a single stimulus (of biologically consistent magnitude) results in maximum common regulator activation. We highlight that such behavior is essential for integrating multiple inputs to produce a stable output regardless of input number. It is also an important, though conditional, example of redundant signaling where multiple signaling pathways lead to the same downstream effect.

Although TSF contains cytokines in addition to IL-8 and CCL2, the connections between the IL-8, CCL2 and IF-induced, integrin- 32 -mediated, signaling appear to suitably explain the in vitro experimentallyobserved macrophage migration. The relatively dominant role of IL-8 and CCL2 is reflected in a second set of experimental data where in vitro antibody blockade of IL-8 and/or CCL2 substantially inhibited the TSF-mediated increase in migration. Moreover, the simultaneous exposure of macrophages to sub-optimal concentrations of both IL-8 and CCL2 was able to achieve a similar effect on migration directedness and speed as their exposure to only TSF. Of note, we recognize that IF and TSF do not appear to act additively in the tumor cell-macrophage co-culture set-up where cytokines are likely to be at saturating levels (confirmed by the similar increase in directedness/speed between the TSF condition and concentration of $100 \mathrm{ng} / \mathrm{mL}$ that was used to intentionally induce saturation, Supplementary Fig. S2). Instead, the increase in directedness/speed with either (1) a combination of IL-8 and CCL2 with each cytokine at a sub-optimal level $(25 \mathrm{ng} / \mathrm{mL})$ or (2) sub-optimal level of either cytokine with IF suggests that synergies are possible at non-saturating cytokine concentrations. Such synergies have been previously demonstrated experimentally for macrophages, and have been determined to depend on the unimpaired activity of both CXCR1/2 and CCR2 receptors, suggesting the intracellular integration of both cytokine signals as the primary synergistic mechanism [75]. 
A comparison of model predictions and in vitro data of these antibody blockade and sub-optimal concentration experiments further validates our network architecture and kinetics assumptions. First, consistent with experiments, the behavior with saturating cytokine concentrations was not observed in response to diminished concentrations. Furthermore, by accurately capturing the signaling instigated by intermediate and sub-optimal cytokine concentrations, our model showed that it is not a simple all-ornothing OR-gate, but a nuanced model that can capture the response across a gradient of stimuli. Second, the model accurately reproduced migration behaviors associated with the antibody blockade of IL-8 and/or CCL2, reinforcing its capability to accurately reproduce experimentally relevant phenomena and capture intermediate signaling with diminished cytokine concentrations (as quantified by the $R^{2}$ values between modelled and in vitro experimental data).

We then conducted a number of sensitivity analyses to determine the most influential aspects of the network on the network response magnitude and the data trends. Stimulus sensitivity analysis revealed that IF was more influential than either cytokine on the concentration of active common regulator, whereas CCL2 was the most influential extracellular stimulus on the directedness and speed trends between various extracellular stimuli (as quantified by the $R^{2}$ values between modelled and in vitro experimental data). Parameter sensitivity analysis then revealed that reactions associated with G protein activation and CCL2 signaling were the most influential on the resulting concentration of active common regulator as well as the trends between various extracellular stimuli (quantified by the $R^{2}$ values between modelled and in vitro experimental data). Also, the activation and turnover of the common regulator itself was important to both active common regulator magnitude and data trends. Notably, although the magnitude of IF velocity has a significant influence on the concentration of active common regulator, the parameters associated with IF signaling were not among the most influential parameters on the concentration of active common regulator.

Importantly, our findings substantiate the idea that IF contributes to cancer invasiveness through enhancing macrophage migration. Indeed, as macrophages would have a heightened capacity to migrate through the 3D ECM, there would be increased likelihood for them to interact with and hence support cancer cell 
migration in the process of metastasis. The supportive function of macrophages toward cancer metastasis was previously demonstrated, where media from tumor-conditioned macrophages increased the expression of EMT genes in a low EMT-score tumor cell line [55]. Moreover, media conditioned from IF-exposed macrophages could increase the speed of cancer cell migration through a 3D matrix [51], suggesting that IF could support the capability of macrophages to promote tumor cell invasion. These findings support the view that macrophages play a pivotal intermediary role between the stimulus of IF and the output of cancer cell invasion through 3D ECM. Notably, other stromal cells in the TME may also respond to IF and further influence macrophage and/or cancer cell migration. For example, cancer associated fibroblasts (CAFs) can secrete ECM to remodel the TME matrix and this can influence cell migration in the TME [120]. Future studies could therefore incorporate other TME-related cells, such as CAFs, to evaluate their contribution to the relationship between IF and the metastasis process.

Therefore, our work presents an integrated in silico-3D in vitro approach to evaluate the effect of IF and TSF on macrophage migration. Here, we developed a signaling network model identifying key stimuli and intermediary proteins that drive macrophage migration, thus identifying potential therapeutic targets for inhibiting macrophage migration (which evidently associates with their capability to support cancer cell invasion). Our model was established using cancer cell lines and macrophages derived from the in vitro differentiation of blood-isolated monocytes. By incorporating patient-derived tumor explants and autologous macrophages, our platform could potentially facilitate high-throughput preclinical screening of therapies for personalized treatment. Our work also forms the basis for developing a companion diagnostic that comes with a biophysical component such as IF for identifying patient responders. In addition, as IF presents a physical barrier to the effective penetration of drugs into deeper regions of the TME, our model could be used to screen and guide the design of therapeutics to optimize their transport efficiency. Importantly, this work contributes toward an improved understanding of the signaling mechanism associating IF, macrophage motility and cancer metastasis, an area that should be studied more extensively to improve cancer treatment. 


\section{Supplementary Material}

Supplementary material is available on the bioRxiv server.

\section{Author Contributions}

S.L., W.S.C., G.A. and R.K. designed the study and in vitro experiments. S.L., G.A. and A.T. conducted in vitro experiments. R.S., F.L. and F.S. developed the computational model. R.S. implemented the model and conducted simulations. D.K. transfected the human cell lines used in the study. S.L. and R.S. analyzed the results. W.S.C., G.A., M.Z. and R.K. supervised the study and acquired funding. All authors interpreted the results, reviewed and edited the manuscript.

\section{Disclosures}

The authors declare no competing interests.

\section{Acknowledgements}

The authors would like to acknowledge the SIgN Multiplex Analysis of proteins (MAP) platform for performing the multiplex cytokine array and $\mathrm{R} \& \mathrm{D}$ systems for performing the protein array of cell culture supernatant. We also thank Vicnesvari T. (Singapore-MIT Alliance for Research and Technology, SMART) for assisting with fabricating microfluidic devices, Giovanni S. Offeddu (Massachusetts Institute of Technology) and Luca Possenti (Politecnico di Milano) for their guidance on performing FRAP analysis and Ran Li (Massachusetts General Hospital) for providing scientific and technical input.

\section{Funding Support}

This work was supported by the National Research Foundation (NRF), Prime Minister's Office, Singapore, under its CREATE program, SMART BioSystems and Micromechanics (BioSyM) IRG [to S.L and R.K.], a core grant to Singapore Immunology Network (SIgN) from Agency for Science, Technology and 
Research (A*STAR) [to S.L., A.T., D. K., W.S.C. and G.A.], the Biomedical Research Council (BMRC)

[IAF 311006 and BMRC transition funds \#H16/99/b0/011 to SIgN Immunomonitoring platform], the National Cancer Institute (NCI) [NCI-U01 CA214381-01 to R.K. and NCI-U01 CA177799 to R.S., F.L., M.Z. and R.K.].

\section{References}

1. Wirtz D, Konstantopoulos K, Searson PC. 2011 The physics of cancer: The role of physical interactions and mechanical forces in metastasis. Nat. Rev. Cancer 11, 512-522.

(doi:10.1038/nrc3080)

2. Stylianopoulos T, Munn LL, Jain RK. 2018 Reengineering the physical microenvironment of tumors to improve drug delivery and efficacy: From mathematical modeling to bench to bedside.

Trends in Cancer 4, 292-319. (doi:10.1016/j.trecan.2018.02.005)

3. K Jain R, Jain RK. 2012 Delivery of molecular and cellular medicine to solid tumors. Adv. Drug Deliv. Rev. 64, 353-365. (doi:10.1016/j.addr.2012.09.011)

4. Jain RK. 1994 Barriers to drug delivery in solid tumors. Sci. Am. 271, 58-65. (doi:10.2307/24942767)

5. Padera TP et al. 2002 Lymphatic metastasis in the absence of functional intratumor lymphatics. Science 296, 1883-1886. (doi:10.1126/science.1071420)

6. Baxter LT, Jain RK. 1989 Transport of fluid and macromolecules in tumors. I. Role of interstitial pressure and convection. Microvasc. Res. 37, 77-104.

7. Baxter LT, Jain RK. 1991 Transport of fluid and macromolecules in tumors. IV. A microscopic model of the perivascular distribution. Microvasc. Res. 41, 252-272.

8. Jain RK, Baxter LT. 1988 Mechanisms of heterogeneous distribution of monoclonal antibodies 
and other macromolecules in tumors: Significance of elevated interstitial pressure. Cancer Res. $\mathbf{4 8 ,}$ $7022-7032$.

9. Jain RK, Tong RT, Munn LL. 2007 Effect of vascular normalization by antiangiogenic therapy on interstitial hypertension, peritumor edema, and lymphatic metastasis: insights from a mathematical model. Cancer Res. 67, 2729-2735. (doi:10.1158/0008-5472.CAN-06-4102)

10. Lichtenbeld HC, Yuan F, Michel CC, Jain RK. 1996 Perfusion of single tumor microvessels: Application to vascular permeability measurement. Microcirculation 3, 349-357. (doi:10.3109/10739689609148307)

11. Milosevic M, Fyles A, Hedley D, Pintilie M, Levin W, Manchul L, Hill R. 2000 Interstitial fluid pressure (IFP) predicts disease-free survival independent of clinical prognostic factors in cervix cancer patients treated with radiotherapy. Int. J. Radiat. Oncol. 48, 135. (doi:10.1016/S03603016(00)80065-6)

12. Nathanson SD, Nelson L. 1994 Interstitial fluid pressure in breast cancer, benign breast conditions, and breast parenchyma. Ann. Surg. Oncol. 1, 333-338. (doi:10.1007/BF03187139)

13. Gutmann R, Leunig M, Feyh J, Goetz AE, Messmer K, Kastenbauer E, Jain RK. 1993 Interstitial hypertension in head and neck tumors in patients: Correlation with tumor size. Cancer Res. 52, 1993-1995.

14. Less JR, Posner MC, Boucher Y, Borochovitz D, Wolmark N, Jain RK. 1992 Interstitial hypertension in human breast and colorectal tumors. Cancer Res. 52, 6371-6374.

15. Roh HD, Boucher Y, Kainicki S, Buchsbaum R, Bloomer WD, Jain RK. 1991 Interstitial hypertension in carcinoma of uterine cervix in patients: Possible correlation with tumor oxygenation and radiation response. Cancer Res. 51, 6695-6698.

16. Lee C-G et al. 2000 Anti-vascular endothelial growth factor treatment augments tumor radiation 
response under normoxic or hypoxic conditions. Cancer Res. 60, 5565-5570.

17. Willett CG et al. 2004 Direct evidence that the VEGF-specific antibody bevacizumab has antivascular effects in human rectal cancer. Nat. Med. 10, 145-147. (doi:10.1038/nm988)

18. Lammerts E, Roswall P, Sundberg C, Gotwals PJ, Koteliansky VE, Reed RK, Heldin NE, Rubin K. 2002 Interference with TGF- $\beta 1$ and $-\beta 3$ in tumor stroma lowers tumor interstitial fluid pressure independently of growth in experimental carcinoma. Int. J. Cancer 102, 453-462. (doi:10.1002/ijc.10722)

19. Pietras K, Stumm M, Hubert M, Buchdunger E, Rubin K, Heldin C-H, McSheehy P, Wartmann M, Östman A. 2003 STI571 enhances the therapeutic index of epothilone B by a tumor-selective increase of drug uptake. Clin. Cancer Res. 9, 3779-3787.

20. Salnikov A V et al. 2003 Lowering of tumor interstitial fluid pressure specifically augments efficacy of chemotherapy. Fed. Am. Soc. Exp. Biol. 17, 1756-1758. (doi:10.1096/fj.02-1201fje)

21. Rubin K, Sjöquist M, Gustafsson A-M, Isaksson B, Salvessen G, Reed RK. 2000 Lowering of tumoral interstitial fluid pressure by prostaglandin E1 is paralleled by an increased uptake of $51 \mathrm{Cr}$ EDTA. Int. J. Cancer 86, 636-643. (doi:10.1002/(SICI)1097-0215(20000601)86:5<636::AIDIJC6>3.0.CO;2-R)

22. Ohno S, Ohno Y, Suzuki N, Kamei T, Koike K, Inagawa H, Kohchi C, Soma GI, Inoue M. 2004 Correlation of histological localization of tumor-associated macrophages with clinicopathological features in endometrial cancer. Anticancer Res. 24, 3335-3342.

(doi:10.1016/j.jbankfin.2005.10.009)

23. Lewis CE, Pollard JW. 2006 Distinct role of macrophages in different tumor microenvironments. Cancer Res. 66, 605-612. (doi:10.1158/0008-5472.CAN-05-4005)

24. Wyckoff JB, Wang Y, Lin EY, Li J-F, Goswami S, Stanley ER, Segall JE, Pollard JW, Condeelis 
J. 2007 Direct visualization of macrophage-assisted tumor cell intravasation in mammary tumors.

Cancer Res. 67, 2649-56. (doi:10.1158/0008-5472.CAN-06-1823)

25. Heldin CH, Rubin K, Pietras K, Östman A. 2004 High interstitial fluid pressure - An obstacle in cancer therapy. Nat. Rev. Cancer 4, 806-813. (doi:10.1038/nrc1456)

26. Hompland T, Ellingsen C, Øvrebø KM, Rofstad EK. 2012 Interstitial fluid pressure and associated lymph node metastasis revealed in tumors by dynamic contrast-enhanced MRI. Cancer Res. 72, 4899-4908. (doi:10.1158/0008-5472.CAN-12-0903)

27. Qian B-Z, Pollard JW. 2010 Macrophage diversity enhances tumor progression and metastasis. Cell 141, 39-51. (doi:10.1016/j.cell.2010.03.014)

28. Bingle L, Brown NJ, Lewis CE. 2002 The role of tumour-associated macrophages in tumour progression: Implications for new anticancer therapies. J. Pathol. 196, 254-265. (doi:10.1002/path.1027)

29. Rutkowski JM, Swartz MA. 2006 A driving force for change: Interstitial flow as a morphoregulator. Trends Cell Biol. 17, 44-50. (doi:10.1016/j.tcb.2006.11.007)

30. Wyckoff $\mathrm{J}$ et al. 2004 A paracrine loop between tumor cells and macrophages is required for tumor cell migration in mammary tumors. Cancer Res. 64, 7022-7029. (doi:10.1158/00085472.CAN-04-1449)

31. Madsen DH et al. 2017 Tumor-associated macrophages derived from circulating inflammatory monocytes degrade collagen through cellular uptake. Cell Rep. 21, 3662-3671. (doi:10.1016/j.celrep.2017.12.011)

32. Opdenakker G, Van Damme J. 1992 Chemotactic factors, passive invasion and metastasis of cancer cells. Immunol. Today 13, 463-464. (doi:10.1016/0167-5699(92)90079-M)

33. Bai J, Adriani G, Dang TM, Tu T uan, Penny HXL, Wong SC, Kamm RD, Thiery JP. 2015 
Contact-dependent carcinoma aggregate dispersion by M2a macrophages via ICAM-1 and $\beta 2$ integrin interactions. Oncotarget 6, 25295-25307. (doi:10.18632/oncotarget.4716)

34. Zervantonakis IK, Hughes-Alford SK, Charest JL, Condeelis JS, Gertler FB, Kamm RD. 2012 Three-dimensional microfluidic model for tumor cell intravasation and endothelial barrier function. Proc. Natl. Acad. Sci. 109, 13515-13520. (doi:10.1073/pnas.1210182109)

35. Seager RJ, Hajal C, Spill F, Kamm RD, Zaman MH. 2017 Dynamic interplay between tumour, stroma and immune system can drive or prevent tumour progression. Converg. Sci. Phys. Oncol. 3, 034002. (doi:10.1088/2057-1739/aa7e86)

36. Li R, Hebert JD, Lee TA, Xing H, Boussommier-Calleja A, Hynes RO, Lauffenburger DA, Kamm RD. 2016 Macrophage-secreted TNFa and TGFb1 influence migration speed and persistence of cancer cells in 3D tissue culture via independent pathways. Cancer Res. 77, 279-290. (doi:10.1158/0008-5472.CAN-16-0442)

37. Ridley AJ. 2001 Rho GTPases and cell migration. J. Cell Sci. 114, 2713-2722.

38. Tanaka T, Terada M, Ariyoshi K, Morimoto K. 2010 Monocyte chemoattractant protein-1/CC chemokine ligand 2 enhances apoptotic cell removal by macrophages through Rac1 activation. Biochem. Biophys. Res. Commun. 399, 677-682. (doi:10.1016/j.bbrc.2010.07.141)

39. Fan H, Hall P, Santos LL, Gregory JL, Fingerle-Rowson G, Bucala R, Morand EF, Hickey MJ. 2011 Macrophage migration inhibitory factor and CD74 regulate macrophage chemotactic responses via MAPK and Rho GTPase. J. Immunol. 186, 4915-4924.

(doi:10.4049/jimmunol.1003713)

40. Oregioni O, Munro P, Flatau G, Mege J-L, Lemichez E, Landraud L, Boyer L, Doye A. 2004 Activation and proteasomal degradation of rho GTPases by cytotoxic necrotizing factor-1 elicit a controlled inflammatory response. J. Biol. Chem. 279, 35849-35857. 
(doi:10.1074/jbc.m401580200)

41. Yamaguchi H, Wyckoff J, Condeelis J. 2005 Cell migration in tumors. Curr. Opin. Cell Biol. 17, 559-564. (doi:10.1016/j.ceb.2005.08.002)

42. Roussos ET, Condeelis JS, Patsialou A. 2011 Chemotaxis in cancer. Nat. Rev. Cancer 11, 573587. (doi:10.1038/nrc3078)

43. Shin Y, Han S, Jeon JS, Yamamoto K, Zervantonakis IK, Sudo R, Kamm RD, Chung S. 2012 Microfluidic assay for simultaneous culture of multiple cell types on surfaces or within hydrogels. Proc. Natl. Acad. Sci. 7, 1247-1259. (doi:10.1038/nprot.2012.051)

44. Polacheck WJ, Zervantonakis IK, Kamm RD. 2013 Tumor cell migration in complex microenvironments. Cell. Mol. Life Sci. 70, 1335-1356. (doi:10.1007/s00018-012-1115-1)

45. Meyer AS, Hughes-Alford SK, Kay JE, Castillo A, Wells A, Gertler FB, Lauffenburger DA. 2012 2D protrusion but not motility predicts growth factor-induced cancer cell migration in 3D collagen. J. Cell Biol. 197, 721-729. (doi:10.1083/jcb.201201003)

46. Fraley SI, Feng Y, Krishnamurthy R, Kim D-H, Celedon A, Longmore GD, Wirtz D. 2010 A distinctive role for focal adhesion proteins in three-dimensional cell motility. Nat. Cell Biol. 12, 598-604. (doi:10.1038/ncb2062)

47. Tung C, Krupa O, Apaydin E, Liou J-J, Diaz-Santana A, Kim BJ, Wu M. 2013 A contact line pinning based microfluidic platform for modelling physiological flows. Lab Chip 13, 3876. (doi:10.1039/c31c50489a)

48. Polacheck WJ, Charest JL, Kamm RD. 2011 Interstitial flow influences direction of tumor cell migration through competing mechanisms. Proc. Natl. Acad. Sci. 108, 11115-11120. (doi:10.1073/pnas.1103581108)

49. Ng CP, Swartz MA. 2003 Fibroblast alignment under interstitial fluid flow using a novel 3-D 
tissue culture model. Am. J. Physiol. - Hear. Circ. Physiol. 284, H1771-H1777.

(doi:10.1152/ajpheart.01008.2002)

50. Ng CP, Hinz B, Swartz MA. 2005 Interstitial fluid flow induces myofibroblast differentiation and collagen alignment in vitro. J. Cell Sci. 118, 4731-4739. (doi:10.1242/jcs.02605)

51. Li R, Serrano JC, Xing H, Lee TA, Azizgolshani H, Zaman M, Kamm RD. 2018 Interstitial flow promotes macrophage polarization toward an M2 phenotype. Mol. Biol. Cell 29, 1927-1940. (doi:10.1091/mbc.E18-03-0164)

52. Kwak B, Altug O, Shin CS, Park K, Bumsoo H. 2014 Simulation of complex transport of nanoparticles around a tumor using tumor-microenvironment-on-chip. J. Control. Release 194, 157-167. (doi:10.1016/j.jconrel.2014.08.027)

53. Spill F, Bakal C, Mak M. 2018 Mechanical and systems biology of cancer. Comput. Struct. Biotechnol. J. 16, 237-245. (doi:10.1016/j.csbj.2018.07.002)

54. Spill F, Reynolds DS, Kamm RD, Zaman MH. 2016 Impact of the physical microenvironment on tumor progression and metastasis. Curr. Opin. Biotechnol. 40, 41-48.

(doi:10.1016/j.copbio.2016.02.007)

55. Penny HL et al. 2016 Warburg metabolism in tumor-conditioned macrophages promotes metastasis in human pancreatic ductal adenocarcinoma. Oncoimmunology 5, 1-15. (doi:10.1080/2162402X.2016.1191731)

56. Adriani G, Ma D, Pavesi A, Kamm RD, Goh ELK. 2017 A 3D neurovascular microfluidic model consisting of neurons, astrocytes and cerebral endothelial cells as a blood-brain barrier. Lab Chip 17, 448-459. (doi:10.1039/c6lc00638h)

57. Lee SWL, Adriani G, Ceccarello E, Pavesi A, Tan AT, Bertoletti A, Kamm RD, Wong SC. 2018 Characterizing the role of monocytes in T cell cancer immunotherapy using a 3D microfluidic 
model. Front. Immunol. 9. (doi:10.3389/fimmu.2018.00416)

58. Sudo R, Chung S, Zervantonakis IK, Vickerman V, Toshimitsu Y, Griffith LG, Kamm RD. 2009

Transport-mediated angiogenesis in 3D epithelial coculture. FASEB J. 23, 2155-2164.

(doi:10.1096/fj.08-122820)

59. Ingalls BP. 2013 Mathematical modeling in systems biology: An introduction. Cambridge, Massachusetts.

60. Alon U. 2006 An introduction to systems biology: Design principles of biological circuits. Chapman and Hall/CRC.

61. Bisswanger H. 2001 Enzyme Kinetics. Wiley-VCH.

62. Suetomi K, Lu Z, Heck T, Wood TG, Prusak DJ, Dunn KJ, Navarro J. 1999 Differential mechanisms of recognition and activation of interleukin-8 receptor subtypes. J. Biol. Chem. 274, 11768-11772. (doi:10.1074/jbc.274.17.11768)

63. Ernst CA, Zhang YJ, Hancock PR, Rutledge BJ, Corless CL, Rollins BJ. 1994 Biochemical and biologic characterization of murine monocyte chemoattractant protein-1. J. Immunol. 152, 35413549.

64. Legewie S, Herzel H, Westerhoff H V, Blüthgen N. 2008 Recurrent design patterns in the feedback regulation of the mammalian signalling network. Mol. Syst. Biol. 4. (doi:10.1038/msb.2008.29)

65. Eden E, Geva-Zatorsky N, Issaeva I, Cohen A, Dekel E, Danon T, Cohen L, Mayo A, Alon U. 2011 Proteome half-life dynamics in living human cells. Science 331, 764-768.

(doi:10.1126/science.1199784)

66. Sham RL, Phatak PD, Ihne TP, Abboud CN, Packman CH. 1993 Signal pathway regulation of interleukin-8-induced actin polymerization in neutrophils. Blood 82, 2546-2551. 
67. Janjanam J, Chandaka GK, Kotla S, Rao GN. 2015 PLC $\beta 3$ mediates cortactin interaction with WAVE2 in MCP1-induced actin polymerization and cell migration. Mol. Biol. Cell 26, 45894606. (doi:10.1091/mbc.E15-08-0570)

68. Waugh DJJ, Wilson C. 2008 The interleukin-8 pathway in cancer. Mol. Pathways 14, 6735-6741. (doi:10.1158/1078-0432.CCR-07-4843)

69. Zhang B et al. 2015 Autocrine IL-8 promotes F-actin polymerization and mediate mesenchymal transition via ELMO1-NF-אB-Snail signaling in glioma. Cancer Biol. Ther. 16, 898-911. (doi:10.1080/15384047.2015.1028702)

70. $\mathrm{Hu}$ Y, Hu X, Boumsell L, Ivashkiv LB. 2008 IFN- $\gamma$ and STAT1 arrest monocyte migration and modulate RAC/CDC42 pathways. J. Immunol. 180, 8057-65.

(doi:10.4049/jimmunol.180.12.8057)

71. Flaishon L et al. 2008 Anti-inflammatory effects of an inflammatory chemokine: CCL2 inhibits lymphocyte homing by modulation of CCL21-triggered integrin-mediated adhesions. Blood 112, 5016-5025. (doi:10.1182/blood-2007-12-129122)

72. Fan H, Hall P, Santos LL, Gregory JL, Fingerle-Rowson G, Bucala R, Morand EF, Hickey MJ. 2011 Macrophage migration inhibitory factor and CD74 regulate macrophage chemotactic responses via MAPK and Rho GTPase. J. Immunol. 186, 4915-4924.

(doi:10.4049/jimmunol.1003713)

73. Sagar D et al. 2017 Antibody blockade of CLEC12A delays EAE onset and attenuates disease severity by impairing myeloid cell CNS infiltration and restoring positive immunity. Sci. Rep. 7. (doi:10.1038/s41598-017-03027-x)

74. Wettschureck N, Offermanns S. 2005 Mammalian G Proteins and Their Cell Type Specific Functions. Physiol. Rev. 85, 1159-1204. (doi:10.1152/physrev.00003.2005) 
75. Gouwy M, Struyf S, Noppen S, Schutyser E, Springael J-Y, Parmentier M, Proost P, Van Damme J. 2008 Synergy between coproduced CC and CXC chemokines in monocyte chemotaxis through receptor-mediated events. Mol. Pharmacol. 74, 485-495. (doi:10.1124/mol.108.045146)

76. Arai H, Charo IF. 1996 Differential regulation of G-protein-mediated signaling by chemokine receptors. J. Biol. Chem. 271, 21814-21819. (doi:10.1074/jbc.271.36.21814)

77. Mitra SK, Hanson DA, Schlaepfer DD. 2005 Focal adhesion kinase: In command and control of cell motility. Nat. Rev. Mol. Cell Biol. 6, 56-68. (doi:10.1038/nrm1549)

78. Michalski CW, Weitz J, Büchler MW. 2007 Surgery Insight: Surgical management of pancreatic cancer. Nat. Clin. Pract. Oncol. 4, 526-535. (doi:10.1038/ncponc0925)

79. Deer EL, González-Hernández J, Coursen JD, Shea JE, Ngatia J, Scaife CL, Firpo MA, Mulvihill SJ. 2010 Phenotype and genotype of pancreatic cancer cell lines. Pancreas 39, 425-435. (doi:10.1097/MPA.0b013e3181c15963)

80. Kurahara H et al. 2011 Significance of M2-polarized tumor-associated macrophage in pancreatic cancer. J. Surg. Res. 167, 211-219. (doi:10.1016/j.jss.2009.05.026)

81. Nywening TM et al. 2018 Targeting both tumour-associated CXCR2+ neutrophils and CCR2+ macrophages disrupts myeloid recruitment and improves chemotherapeutic responses in pancreatic ductal adenocarcinoma. Gut 67, 1112-1123. (doi:10.1136/gutjnl-2017-313738)

82. Li N et al. 2016 Hypoxia inducible factor 1 (HIF-1) recruits macrophage to activate pancreatic stellate cells in pancreatic ductal adenocarcinoma. Int. J. Mol. Sci. 17, 799. (doi:10.3390/ijms17060799)

83. Ino Y, Yamazaki-Itoh R, Shimada K, Iwasaki M, Kosuge T, Kanai Y, Hiraoka N. 2013 Immune cell infiltration as an indicator of the immune microenvironment of pancreatic cancer. $B r . J$.

Cancer 108, 914. (doi:10.1038/bjc.2013.32) 
84. Candido JB et al. 2018 CSF1R+ Macrophages Sustain Pancreatic Tumor Growth through T Cell Suppression and Maintenance of Key Gene Programs that Define the Squamous Subtype. Cell Rep. 23, 1448-1460. (doi:10.1016/j.celrep.2018.03.131)

85. Torres C et al. 2015 Prognosis relevance of serum cytokines in pancreatic cancer. Biomed Res. Int. (doi:10.1155/2015/518284)

86. Babic A et al. 2018 Plasma inflammatory cytokines and survival of pancreatic cancer patients Open. Clin. Transl. Gastroenterol. 9, 145. (doi:10.1038/s41424-018-0008-5)

87. Błogowski W, Deskur A, Budkowska M, Sałata D, Madej-Michniewicz A, Dabkowski K, Dołe B, Starzynska T. 2014 Selected cytokines in patients with pancreatic cancer: A preliminary report. PLoS One 9, e97613. (doi:10.1371/journal.pone.0097613)

88. Yako YY, Kruger D, Smith M, Brand M. 2016 Cytokines as biomarkers of pancreatic ductal adenocarcinoma: A systematic review. PLoS One 11, 154016. (doi:10.1371/journal.pone.0154016)

89. Sun M, Zaman MH. 2017 Modeling, signaling and cytoskeleton dynamics: integrated modelingexperimental frameworks in cell migration. Wiley Interdiscip. Rev. Syst. Biol. Med. 9, 1365. (doi:10.1002/wsbm.1365)

90. Kim M-C, Silberberg YR, Abeyaratne R, Kamm RD, Asada HH. 2018 Computational modeling of three-dimensional ECM-rigidity sensing to guide directed cell migration. Proc. Natl. Acad. Sci. 115, E390-E399. (doi:10.1073/pnas.1717230115)

91. Mark C, Metzner C, Lautscham L, Strissel PL, Strick R, Fabry B. 2018 Bayesian model selection for complex dynamic systems. Nat. Commun. 9, 1803. (doi:10.1038/s41467-018-04241-5)

92. Mak M, Spill F, Kamm RD, Zaman MH. 2016 Single-cell migration in complex microenvironments: Mechanics and aignaling dynamics. J. Biomech. Eng. 138, 021004. (doi:10.1115/1.4032188) 
93. Murphy C et al. 2005 Nonapical and Cytoplasmic Expression of Interleukin-8, CXCR1, and CXCR2 Correlates with Cell Proliferation and Microvessel Density in Prostate Cancer. Clin Cancer Res. 11.

94. Venkatakrishnan G, Salgia R, Groopman JE. 2000 Chemokine receptors CXCR-1/2 activate mitogen-activated protein kinase via the epidermal growth factor receptor in ovarian cancer cells. J. Biol. Chem. 275, 6868-6875. (doi:10.1074/jbc.275.10.6868)

95. Xu H, Lai W, Zhang Y, Liu L, Luo X, Zeng Y, Wu H, Lan Q, Chu Z. 2014 Tumor-associated macrophage-derived IL-6 and IL-8 enhance invasive activity of LoVo cells induced by PRL-3 in a KCNN4 channel-dependent manner. BMC Cancer 14, 330. (doi:10.1186/1471-2407-14-330)

96. Fu XT et al. 2015 Macrophage-secreted IL-8 induces epithelial-mesenchymal transition in hepatocellular carcinoma cells by activating the JAK2/STAT3/Snail pathway. Int. J. Oncol. 46, 587-596. (doi:10.3892/ijo.2014.2761)

97. Araki S, Omori Y, Lyn D, Singh RK, Meinbach DM, Sandman Y, Lokeshwar VB, Lokeshwar BL. 2007 Interleukin-8 is a molecular determinant of androgen independence and progression in prostate cancer. Cancer Res. 67, 6854-6862. (doi:10.1158/0008-5472.CAN-07-1162)

98. Yao C, Lin Y, Chua MS, Ye CS, Bi J, Li W, Zhu YF, Wang SM. 2007 Interleukin-8 modulates growth and invasiveness of estrogen receptor-negative breast cancer cells. Int. J. Cancer 121, 1949-1957. (doi:10.1002/ijc.22930)

99. Lang K, Niggemann B, Zanker KS, Entschladen F. 2002 Signal processing in migrating T24 human bladder carcinoma cells: Role of the autocrine interleukin-8 loop. Int. J. Cancer 99, 673680. (doi:10.1002/ijc.10424)

100. Huang S, Mills L, Mian B, Tellez C, Mccarty M, Yang X-D, Gudas JM, Bar-Eli M. 2002 Fully humanized neutralizing antibodies to interleukin-8 (ABX-IL8) inhibit angiogenesis, tumor growth, 
and metastasis of human melanoma. Am. J. Pathol. 161, 125-134. (doi:10.1016/S0002-

9440(10)64164-8)

101. Shi Q, Abbruzzese JL, Huang S, Fidler IJ, Xiong Q, Xie K. 1999 Constitutive and inducible interleukin 8 expression by hypoxia and acidosis renders human pancreatic cancer cells more tumorigenic and metastatic. Clin Cancer Res 5, 3711-3721.

102. Inoue K et al. 2000 Interleukin 8 expression regulates tumorigenicity and metastases in androgenindependent prostate cancer. Clin Cancer Res 6, 2104-2119.

103. Karashima TF-BMA and M of HBC through the R of I-8 1 et al. 2003 Nuclear factor-kB mediates angiogenesis and metastasis of human bladder cancer through the regulation of interleukin-8. Clin Cancer Res 9, 2786-2797.

104. Mian BM, Dinney CPN, Bermejo CE, Sweeney P, Tellez C, Yang XD, Gudas JM, McConkey DJ, Bar-Eli M. 2003 Fully human anti-interleukin 8 antibody inhibits tumor growth in orthotopic bladder cancer xenografts via down-regulation of matrix metalloproteases and nuclear factor- $\kappa \mathrm{B}$. Clin. Cancer Res. 9, 3167-3175.

105. Inoue K, Slaton JW, Kim SJ, Perrotte P, Eve BY, Bar-Eli M, Radinsky R, Dinney CPN. 2000 Interleukin 8 expression regulates tumorigenicity and metastasis in human bladder cancer. Cancer Res. 60, 2290-2299.

106. Yuan A, Yang P-C, Yu C-J, Chen W-J, Lin F-Y, Kuo S-H, Luh K-T. 2000 nterleukin-8 messenger ribonucleic acid expression correlates with tumor progression, tumor angiogenesis, patient survival, and timing of relapse in non-small-cell lung cancer. Am J Respir Crit Care Med 162, 1957-1963. (doi:10.1164/ajrccm.162.5.2002108)

107. Fernando RI, Hamilton DH, Dominguez C, David JM, Mccampbell KK, Palena C. 2016 IL-8 signaling is involved in resistance of lung carcinoma cells to erlotinib. Oncotarget 7, 42031- 
42044. (doi:10.18632/oncotarget.9662)

108. Mizutani K, Sud S, Mcgregor NA, Martinovski G, Rice BT, Craig MJ, Varsos ZS, Roca H, Pienta KJ. 2009 The chemokine CCL2 increases prostate tumor growth and bone metastasis through macrophage and osteoclast recruitment. Neoplasia 11, 1235-1242. (doi:10.1593/neo.09988)

109. Loberg RD, Ying C, Craig M, Yan L, Snyder LA, Pienta KJ. 2007 CCL2 as an important mediator of prostate cancer growth in vivo through the regulation of macrophage infiltration. Neoplasia $\mathbf{9}$, 556-562. (doi:10.1593/neo.07307)

110. Conti I, Rollins BJ. 2004 CCL2 (monocyte chemoattractant protein-1) and cancer. Semin. Cancer Biol. 14, 149-154. (doi:10.1016/j.semcancer.2003.10.009)

111. Ueno T, Toi M, Saji H, Muta M, Bando H, Kuroi K, Koike M, Inadera H, Matsushima K. 2000 Significance of macrophage chemoattractant protein-1 in macrophage recruitment, angiogenesis, and survival in human breast cancer. Clin. Cancer Res. 6, 3282-3289.

112. Graves DT, Barnhill R, Galanopoulos T, Antoniades HN. 1992 Expression of monocyte chemotactic protein-1 in human melanoma in vivo. Am. J. Pathol. 140, 9-14.

113. Negus RPM et al. 2015 The detection and localization of monocyte chemoattractant protein-1 (MCP-1) in human ovarian cancer. J. Clin. Invest. 95, 2391-2396. (doi:10.1172/JCI117933)

114. Riethdorf L, Riethdorf S, Gutzlaff K, Prall F, Loning T. 1996 Differential Expression of the Monocyte Chemoattractant Protein-1 Gene in Human Papillomavirus-16-Infected Squamous Intraepithelial Lesions and Squamous Cell Carcinomas of the Cervix Uteri. Am. J. ofPathology 149, 1469.

115. Sanford DE et al. 2013 Inflammatory monocyte mobilization decreases patient survival in pancreatic cancer: A role for targeting the CCL2/CCR2 axis. Clin. Cancer Res. 19, 3404-3415. (doi:10.1158/1078-0432.CCR-13-0525) 
116. Vicari AP, Caux C. 2001 Chemokines in cancer. Cytokine Growth Factor Rev. 13, 143-154. (doi:10.1016/S1359-6101(01)00033-8)

117. Arya M, Patel HRH, Williamson M. 2003 Chemokines: Key players in cancer. Curr. Med. Res. Opin. 19, 557-564. (doi:10.1185/030079903125002216)

118. Shyy JYJ, Chien S. 2002 Role of integrins in endothelial mechanosensing of shear stress. Circ. Res. 91, 769-775. (doi:10.1161/01.RES.0000038487.19924.18)

119. Terashima Y et al. 2005 Pivotal function for cytoplasmic protein FROUNT in CCR2-mediated monocyte chemotaxis. Nat. Immunol. 6, 827-835. (doi:10.1038/ni1222)

120. Joyce JA, Fearon DT. 2015 T cell exclusion, immune privilege and the tumour microenvironment. Science 348, 74-80. (doi:10.1126/science.aaa6204) 

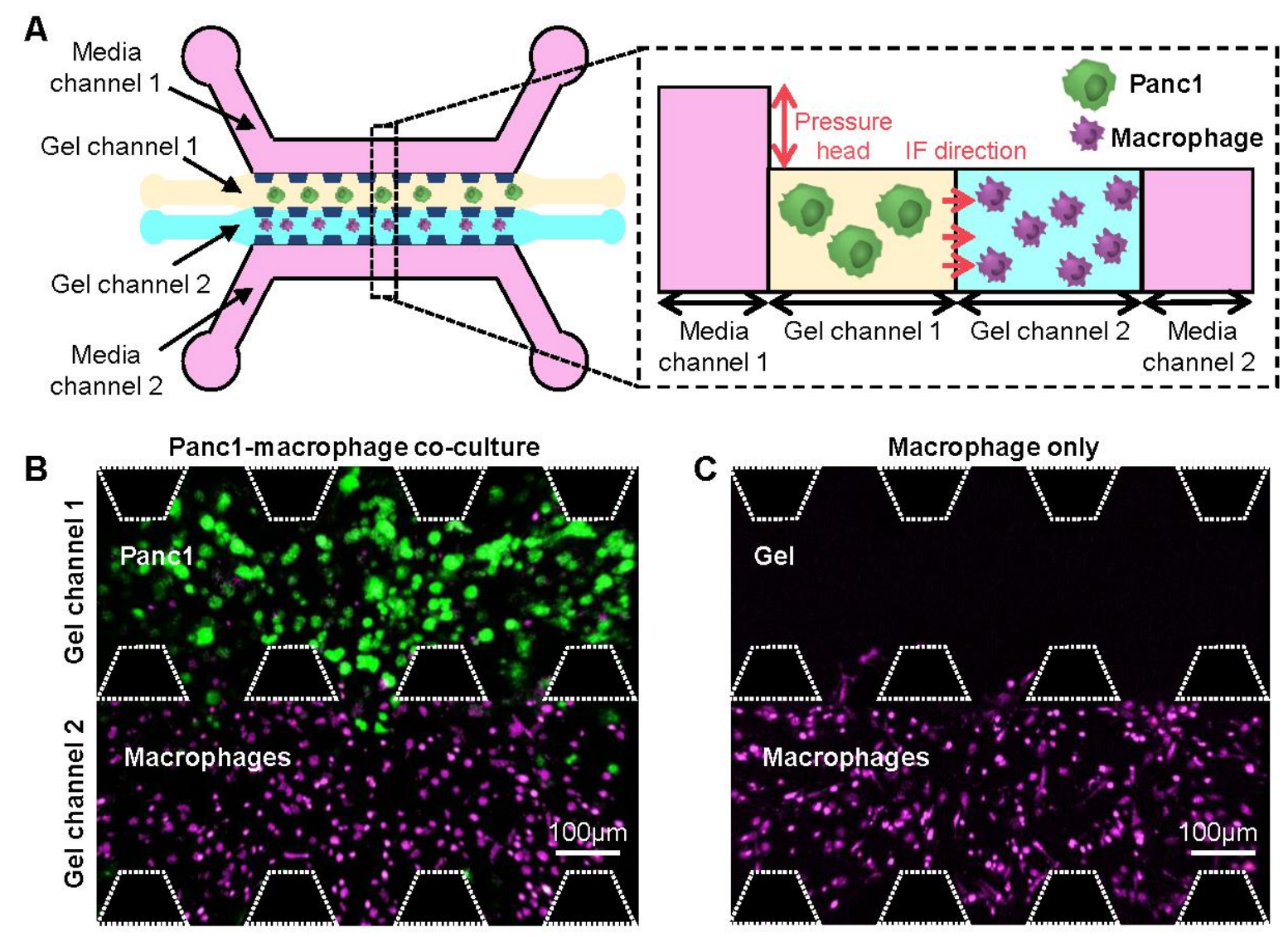

Figure 1. (A) Design of microfluidic co-culture model of tumor cells (Panc1) and macrophages with the incorporation of interstitial flow (IF). Representative confocal image of cell-seeded gel channels at $0 \mathrm{~h}$ (B) with tumor cells or (C) without tumor cells. 

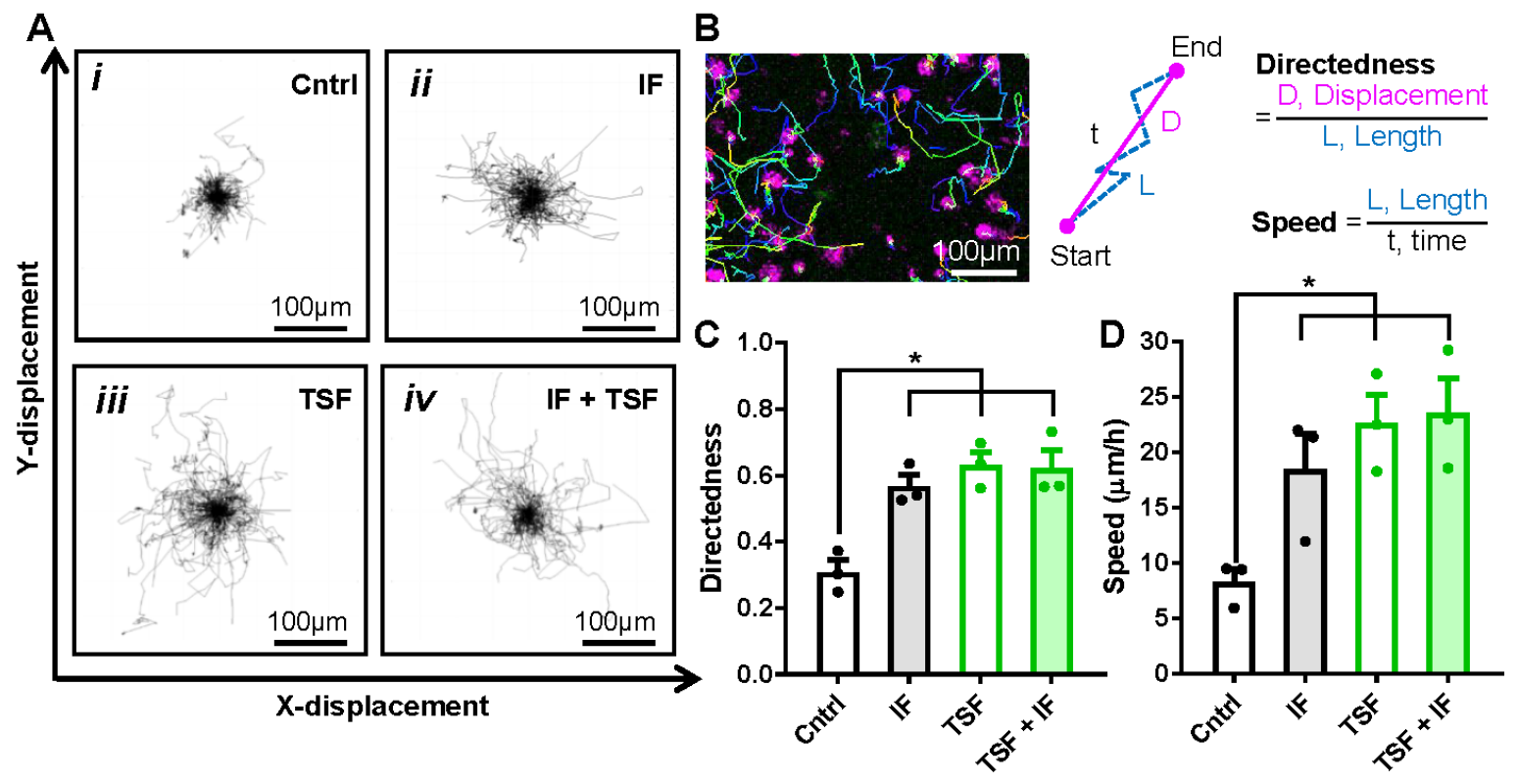

Figure 2. (A) X-Y path trajectories of macrophage migration in the (i) control (Cntrl) monoculture of macrophages without interstitial flow (IF) or exposed to (ii) only IF, (iii) only tumor cells; tumor-secreted factors (TSF), or (iv) both IF and TSF. (B) Quantification method of macrophage migration directedness and speed. (C) Directedness and (D) speed of macrophage migration under the different conditions tested. Data are shown as the mean \pm SEM $(n=3)$, where statistical significance was determined using a one-way ANOVA with Holm-Sidak's multiple comparisons test with $* P \leq 0.05$. 
A

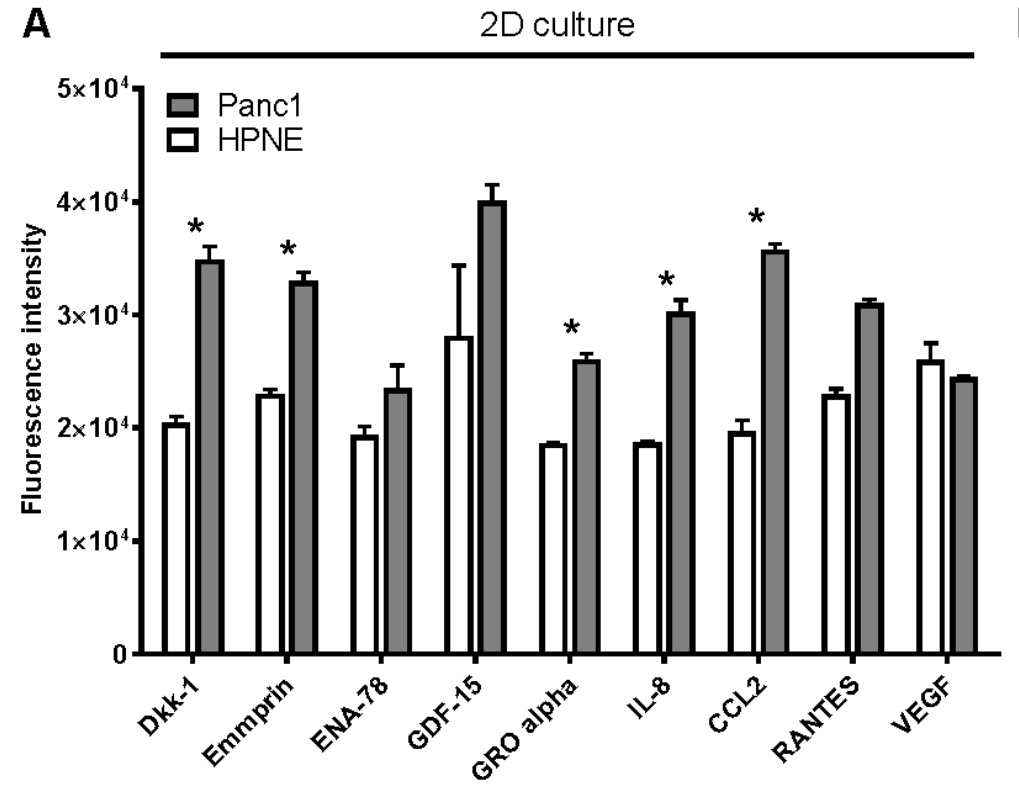

B 3D culture

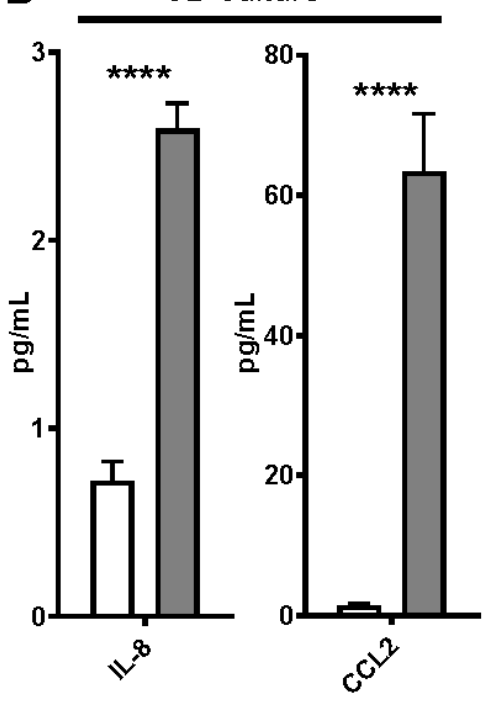

Figure 3. Multiplex array of cytokines in culture supernatant derived (A) from cells grown as a 2D monolayer using the Proteome Profiler ${ }^{\mathrm{TM}}$ antibody array (R\&D Systems) or (B) from cells grown in a 3D matrix environment using the Milliplex 38 Cytokine kit (Millipore). Data are shown as the mean \pm SEM (n $=3$ ), where statistical significance was determined using a Student's $t$-test with $* P \leq 0.05$ and **** $P \leq$ 0.0001 . 


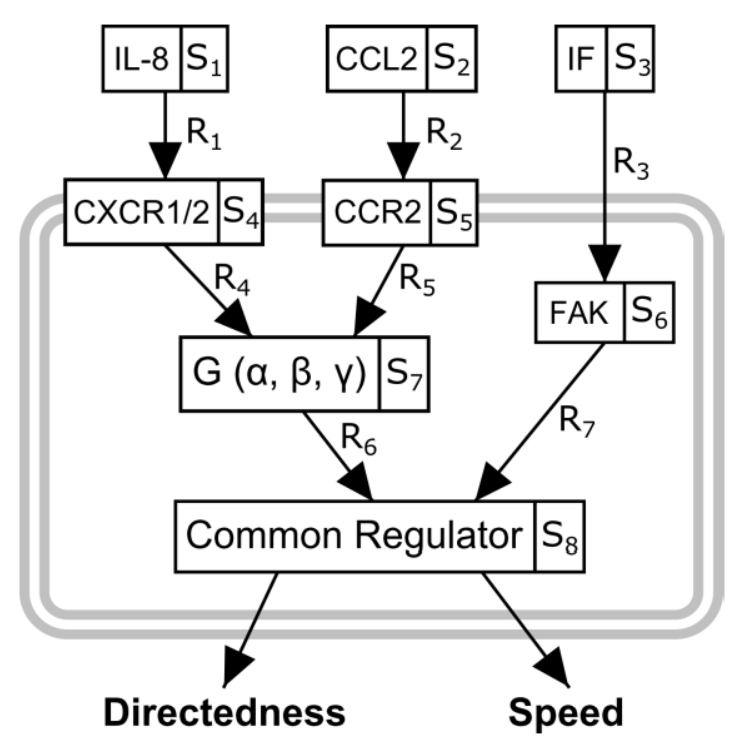

Figure 4. Hypothesized signaling model showing how signals associated with IL-8, CCL2 and interstitial flow (IF) activate a common regulator, both individually and in combination, to regulate macrophage migration directedness and speed. The input stimuli (IL-8, CCL2 and IF), associated cytokine receptors (CXCR1/2 and CCR2) and intermediary signaling species, including focal adhesion kinase (FAK) and heterotrimeric small G-proteins, $\mathrm{G}(\alpha, \beta, \gamma)$, are identified by their respective abbreviations and species variables (Eq. 2-10 in section 'Mathematical model development'). 
A
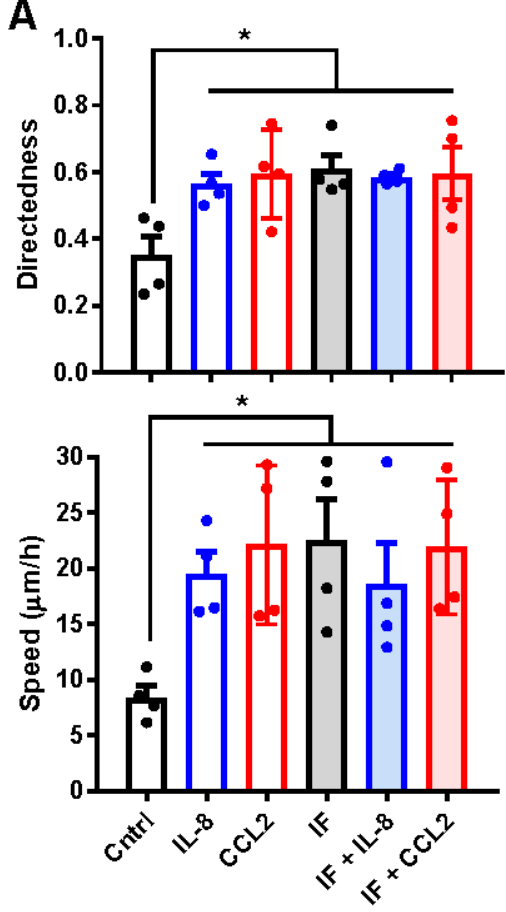

B
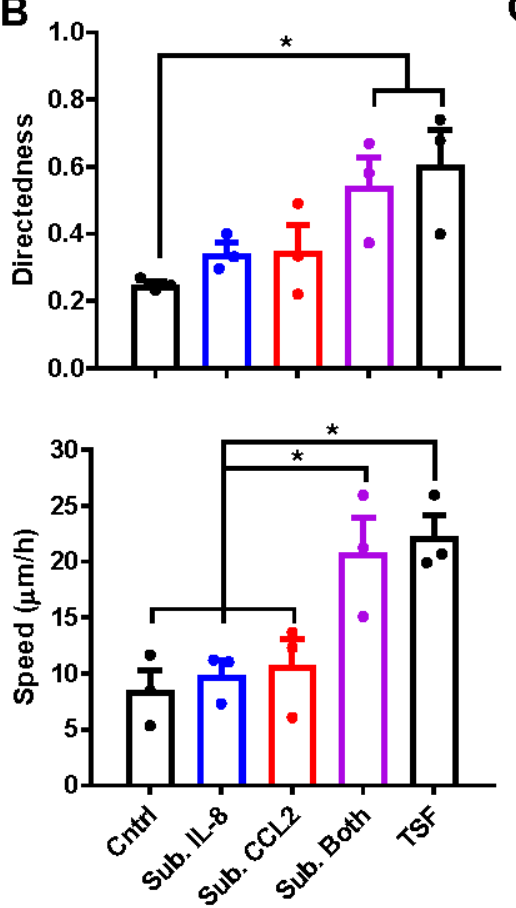
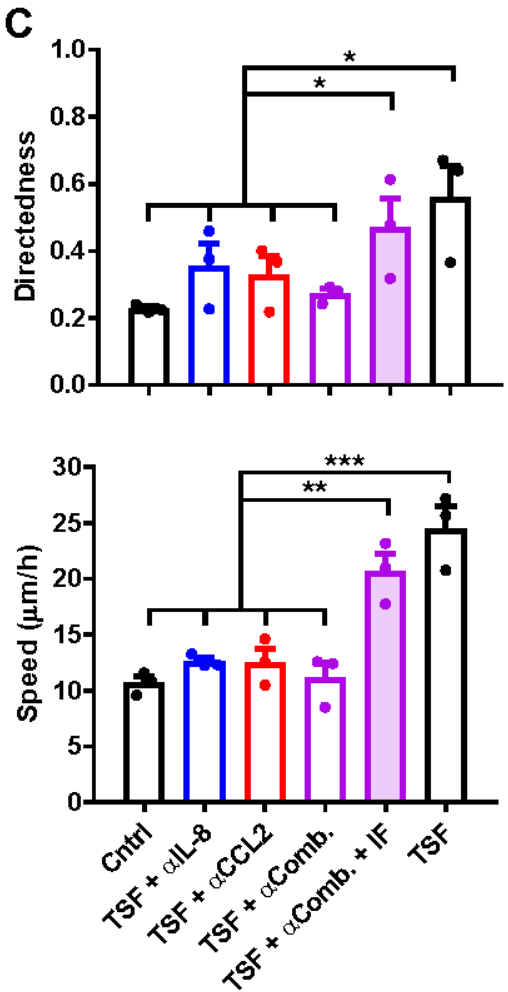

Figure 5. Directedness (top panel) and speed (bottom panel) of macrophage migration with exogenous addition of a (A) saturating concentration $(100 \mathrm{ng} / \mathrm{mL})$ of IL-8 or CCL2, or (B) sub-optimal concentration $(25 \mathrm{ng} / \mathrm{mL})$ of IL-8 and/or CCL2 to a macrophage monoculture, or the addition of (C) blocking antibodies against IL-8 and/or CCL2 to a macrophage-tumor cell co-culture in the presence or absence of IF. Data are shown as the mean $\pm \operatorname{SEM}(\mathrm{n} \geq 3)$, where statistical significance was determined using a one-way ANOVA with Holm-Sidak's multiple comparisons test with * $P \leq 0.05$, ** $P \leq 0.01$, and *** $P \leq 0.001$. (Cntrl: control, IF: interstitial flow, Sub.: sub-optimal, Sub. Both: combined addition of sub-optimal concentrations of IL-8 and CCL2, TSF: tumor-secreted factors, $\alpha$ Comb.: combined blockade of IL-8 and CCL2) 

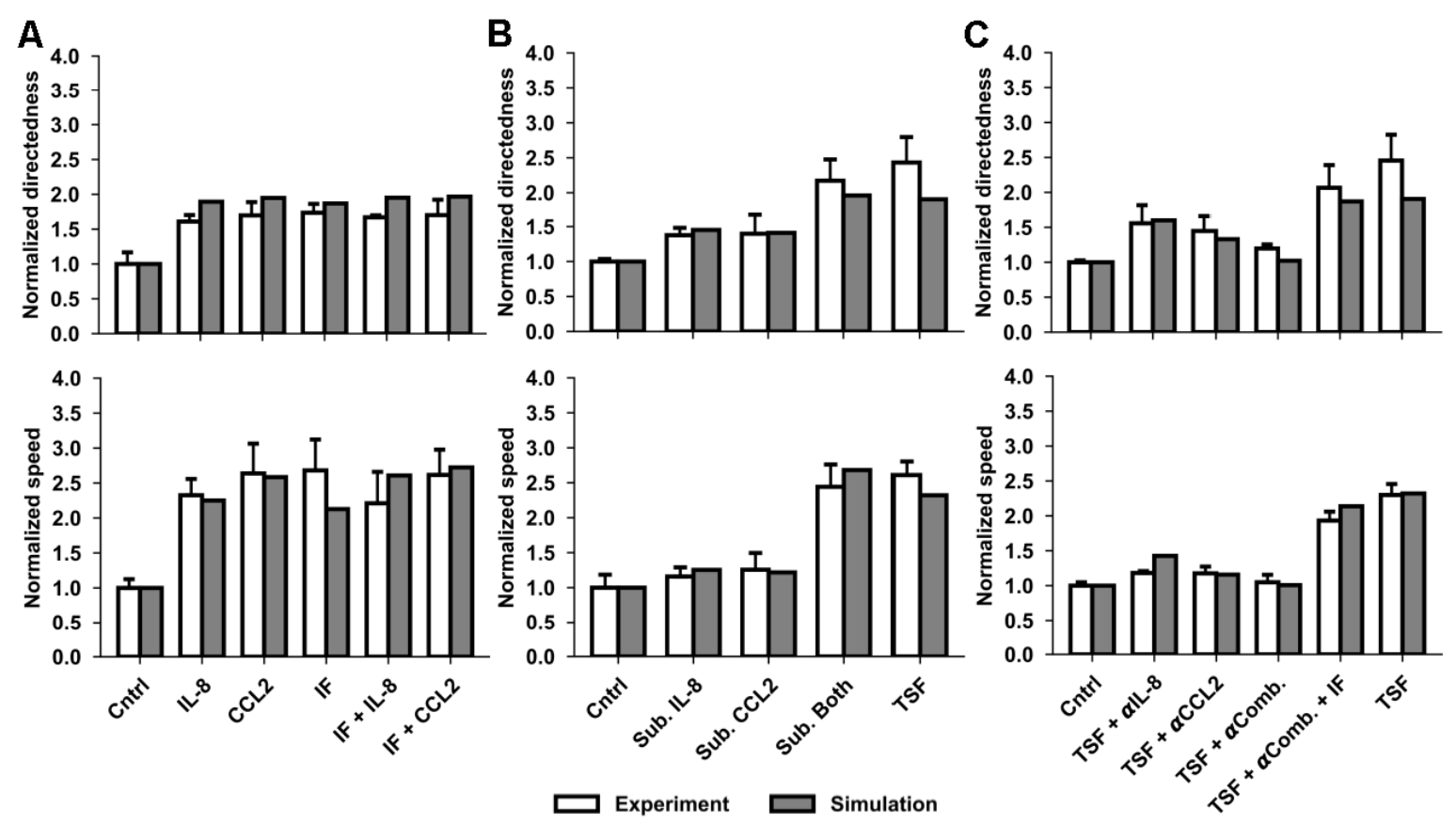

Figure 6. Non-significant difference between in vitro experimental (white) and model (grey) predictions for normalized directedness (top panel) and speed (bottom panel) of macrophage migration with exogenous addition of a (A) saturating concentration $(100 \mathrm{ng} / \mathrm{mL})$ of IL-8 or CCL2, or (B) sub-optimal concentration $(25 \mathrm{ng} / \mathrm{mL})$ of IL-8 and/or CCL2 to a macrophage monoculture, or the addition of (C) blocking antibodies against IL-8 and/or CCL2 to a macrophage-tumor cell co-culture in the presence or absence of IF (100\% antibody blockade of cytokines assumed). Data are shown as the mean \pm SEM ( $\geq 23)$, where statistical significance was determined using Student's $t$-tests which compared between in vitro experimental data and model-generated data at a pointwise level with $P \leq 0.05$. (Cntrl: control, IF: interstitial flow, Sub.: suboptimal, Sub. Both: combined addition of sub-optimal concentrations of IL-8 and CCL2, TSF: tumorsecreted factors, $\alpha$ Comb.: combined blockade of IL-8 and CCL2) 

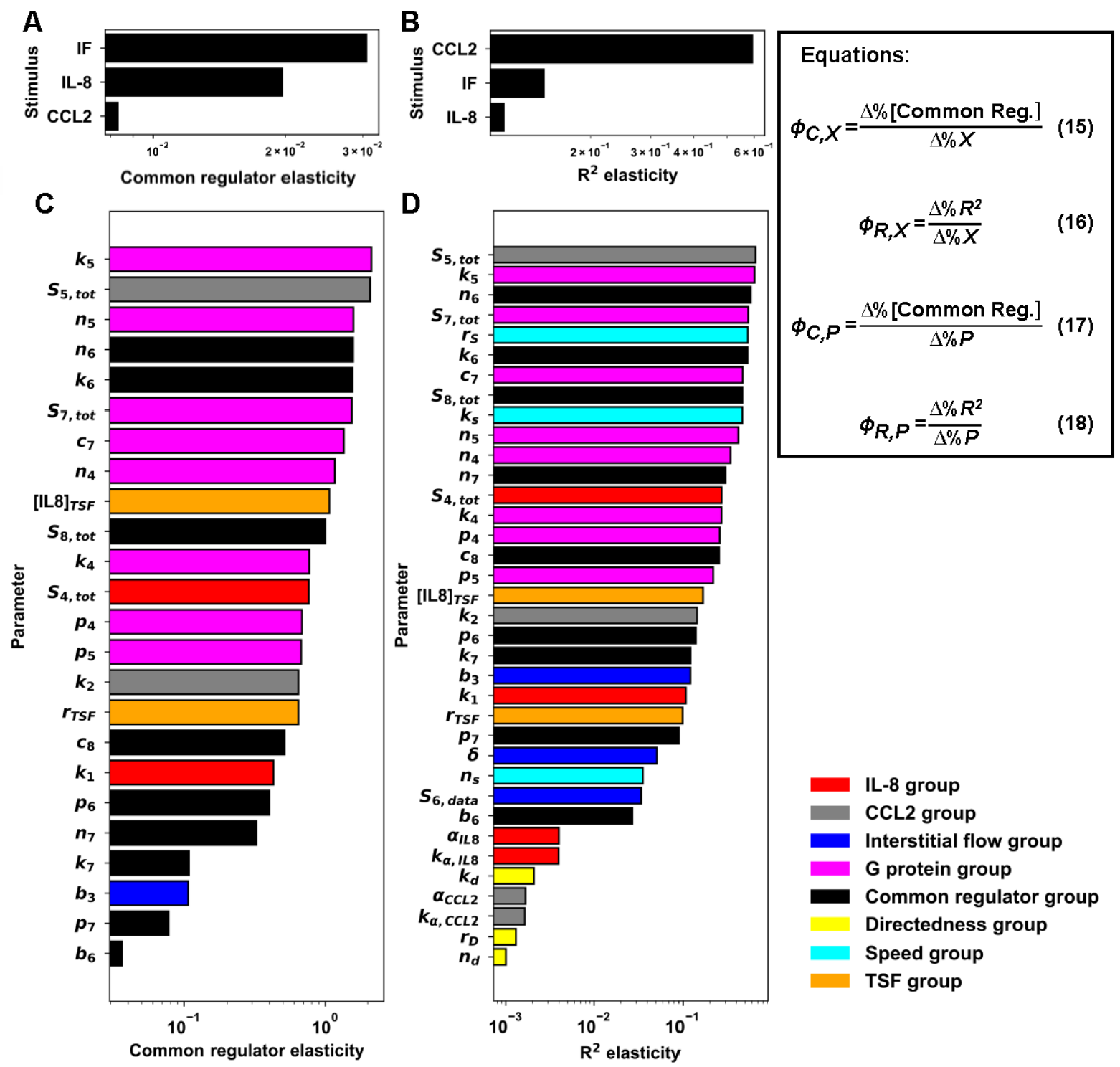

D
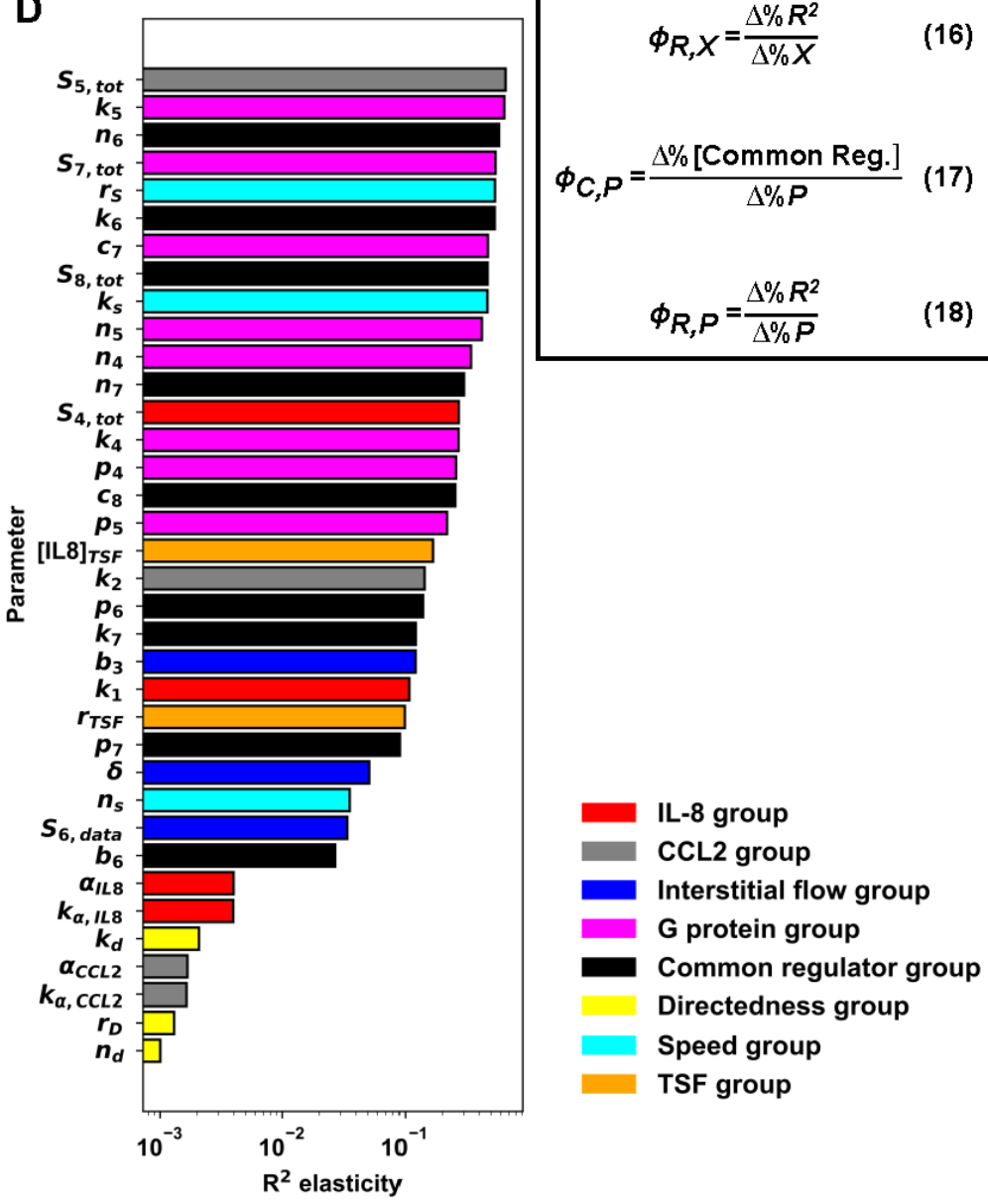

Figure 7. Sensitivity analysis that quantifies most influential stimuli and parameters on migration directedness and speed. The analysis considered (A) common regulator activation elasticity (Eq. 15) or (B) coefficient of determination $\left(R^{2}\right)$ elasticity (Eq. 16) in response to varying the magnitude of each extracellular stimulus. Also considered was (C) common regulator activation elasticity (Eq. 17) or (D) $R^{2}$ elasticity (Eq. 18) in response to varying the magnitude of each parameter. The denominators $\Delta \% X$ and $\Delta \% P$ respectively represent a $20 \%$ change in the stimulus or the parameter under study. The numerator $\Delta \%$ [Common Reg.] and $\Delta \% R^{2}$ respectively represent the resulting percent change in concentration of active common regulator or the $R^{2}$ value between the model predictions and the in vitro experimental data. All plots are base-10 log scale. 